Cochrane Database of Systematic Reviews

\title{
External cephalic version for breech presentation at term (Review)
}

Hofmeyr GJ, Kulier R, West HM

Hofmeyr GJ, Kulier R, West HM.

External cephalic version for breech presentation at term.

Cochrane Database of Systematic Reviews 2015, Issue 4. Art. No.: CD000083.

DOI: 10.1002/14651858.CD000083.pub3.

www.cochranelibrary.com 
TABLE OF CONTENTS

ABSTRAC 1

PLAIN LANGUAGE SUMMARY

SUMMARY OF FINDINGS

BACKGROUND

OBJECTIVES

METHODS

RESULTS

Figure 1.

Figure 2.

DISCUSSION

AUTHORS' CONCLUSIONS

ACKNOWLEDGEMENTS

REFERENCES

\section{CHARACTERISTICS OF STUDIES}

DATA AND ANALYSES

Analysis 1.1. Comparison 1 External cephalic version at term versus no ECV attempt, Outcome 1 Vaginal cephalic birth not achieved (CS + breech vaginal birth) (not prespecified).

Analysis 1.2. Comparison 1 External cephalic version at term versus no ECV attempt, Outcome 2 Caesarean section.

Analysis 1.3. Comparison 1 External cephalic version at term versus no ECV attempt, Outcome 3 Non-cephalic presentation at birth.

Analysis 1.4. Comparison 1 External cephalic version at term versus no ECV attempt, Outcome 4 Vaginal breech birth (not prespecified).

Analysis 1.5. Comparison 1 External cephalic version at term versus no ECV attempt, Outcome 5 Apgar score $<7$ at 1 minute (not prespecified).

Analysis 1.6. Comparison 1 External cephalic version at term versus no ECV attempt, Outcome 6 Apgar score $<7$ at 5 minutes. .. Analysis 1.7. Comparison 1 External cephalic version at term versus no ECV attempt, Outcome 7 Umbilical vein $\mathrm{pH}<7.20$. ..... Analysis 1.8. Comparison 1 External cephalic version at term versus no ECV attempt, Outcome 8 Perinatal death.

Analysis 1.9. Comparison 1 External cephalic version at term versus no ECV attempt, Outcome 9 Neonatal admission. ........... Analysis 1.10. Comparison 1 External cephalic version at term versus no ECV attempt, Outcome 10 Enrolment-delivery interval (not prespecified).

Analysis 2.1. Comparison 2 Sensitivity analysis (excluding studies with high risk of bias), Outcome 1 Vaginal cephalic birth not achieved (CS + breech vaginal birth).

Analysis 2.2. Comparison 2 Sensitivity analysis (excluding studies with high risk of bias), Outcome 2 Caesarean section. ........ Analysis 2.3. Comparison 2 Sensitivity analysis (excluding studies with high risk of bias), Outcome 3 Non cephalic presentation at birth.

Analysis 2.4. Comparison 2 Sensitivity analysis (excluding studies with high risk of bias), Outcome 4 Vaginal breech birth. .....

Analysis 3.1. Comparison 3 Sensitivity analysis (excluding studies in Africa), Outcome 1 Vaginal cephalic birth not achieved (CS + breech vaginal birth).

Analysis 3.2. Comparison 3 Sensitivity analysis (excluding studies in Africa), Outcome 2 Caesarean section. ............................ Analysis 3.3. Comparison 3 Sensitivity analysis (excluding studies in Africa), Outcome 3 Non cephalic presentation at birth. ....

Analysis 3.4. Comparison 3 Sensitivity analysis (excluding studies in Africa), Outcome 4 Vaginal breech birth.

APPENDICES

WHAT'S NEW

HISTORY

CONTRIBUTIONS OF AUTHORS

DECLARATIONS OF INTEREST

SOURCES OF SUPPORT

DIFFERENCES BETWEEN PROTOCOL AND REVIEW

INDEX TERMS 
[Intervention Review]

\title{
External cephalic version for breech presentation at term
}

\author{
G Justus Hofmeyr ${ }^{1}$, Regina Kulier ${ }^{2}$, Helen M West ${ }^{3}$
}

1 Walter Sisulu University, University of Fort Hare, University of the Witwatersrand, Eastern Cape Department of Health, East London, South Africa. 2 Profa Consultation de sante sexuelle, Morges, Switzerland. ${ }^{3}$ nstitute of Psychology, Health and Society, The University of Liverpool, Liverpool, UK

Contact: G Justus Hofmeyr, Walter Sisulu University, University of Fort Hare, University of the Witwatersrand, Eastern Cape Department of Health, East London, South Africa. justhof@gmail.com.

Editorial group: Cochrane Pregnancy and Childbirth Group.

Publication status and date: Edited (no change to conclusions), published in Issue 5, 2019.

Citation: Hofmeyr GJ, Kulier R, West HM. External cephalic version for breech presentation at term. Cochrane Database of Systematic Reviews 2015, Issue 4. Art. No.: CD000083. DOI: 10.1002/14651858.CD000083.pub3.

Copyright @ 2019 The Cochrane Collaboration. Published by John Wiley \& Sons, Ltd.

\section{A B S T R A C T}

\section{Background}

Management of breech presentation is controversial, particularly in regard to manipulation of the position of the fetus by external cephalic version (ECV). ECV may reduce the number of breech presentations and caesarean sections, but there also have been reports of complications with the procedure.

\section{Objectives}

The objective of this review was to assess the effects of ECV at or near term on measures of pregnancy outcome. Methods of facilitating ECV, and ECV before term are reviewed separately.

\section{Search methods}

We searched the Cochrane Pregnancy and Childbirth Trials Register (28 February 2015) and reference lists of retrieved studies.

\section{Selection criteria}

Randomised trials of ECV at or near term (with or without tocolysis) compared with no attempt at ECV in women with breech presentation.

\section{Data collection and analysis}

Two review authors assessed eligibility and trial quality, and extracted the data.

\section{Main results}

We included eight studies, with a total of 1308 women randomised. The pooled data from these studies show a statistically significant and clinically meaningful reduction in non-cephalic presentation at birth (average risk ratio (RR) $0.42,95 \%$ confidence interval (CI) 0.29 to 0.61 , eight trials, 1305 women); vaginal cephalic birth not achieved (average RR $0.46,95 \% \mathrm{Cl} 0.33$ to 0.62 , seven trials, 1253 women, evidence graded very low); and caesarean section (average RR $0.57,95 \% \mathrm{Cl} 0.40$ to 0.82 , eight trials, 1305 women, evidence graded very low) when ECV was attempted in comparison to no ECV attempted. There were no significant differences in the incidence of Apgar score ratings below seven at one minute (average RR $0.67,95 \% \mathrm{Cl} 0.32$ to 1.37 , three trials, 168 infants) or five minutes (RR $0.63,95 \% \mathrm{Cl} 0.29$ to 1.36 , five trials, 428 infants, evidence graded very low), low umbilical vein pH levels (RR $0.65,95 \% \mathrm{Cl} 0.17$ to 2.44 , one trial, 52 infants, evidence graded very low), neonatal admission (RR $0.80,95 \% \mathrm{Cl} 0.48$ to 1.34, four trials, 368 infants, evidence graded very low), perinatal death (RR 0.39 , $95 \% \mathrm{Cl} 0.09$ to 1.64 , eight trials, 1305 infants, evidence graded low), nor time from enrolment to delivery (mean difference -0.25 days, $95 \%$ $\mathrm{Cl}-2.81$ to 2.31 , two trials, 256 women). 
All of the trials included in this review had design limitations, and the level of evidence was graded low or very low. No studies attempted to blind the intervention, and the process of random allocation was suboptimal in several studies. Three of the eight trials had serious design limitations, however excluding these studies in a sensitivity analysis for outcomes with substantial heterogeneity did not alter the results.

\section{Authors' conclusions}

Attempting cephalic version at term reduces the chance of non-cephalic presentation at birth, vaginal cephalic birth not achieved and caesarean section. There is not enough evidence from randomised trials to assess complications of ECV at term. Large observational studies suggest that complications are rare.

A visual summary of some of the results from this review can be found here.

\section{PLAIN LANGUAGE SUMMARY}

Effects of turning unborn babies from bottom first to head first at the end of pregnancy (around 36 weeks or more) for reducing problems during childbirth

\section{What is the issue?}

The best outcomes in childbirth for both mothers and babies are when the baby is born head-first. If the baby is in another position, there is a higher risk of complications including the need for caesarean section. In a 'breech presentation' the baby is bottom-down instead of head-down. External cephalic version (ECV) is a technique for turning the unborn baby so it lies head-down. This review looked at the effects of using ECV on babies that were in the breech position at the end of pregnancy (around 36 weeks or more).

\section{Why is this important?}

Everyone wants to avoid complications in childbirth and many women want to avoid having a caesarean section. Avoiding the need for surgery is very important in countries with limited resources for healthcare. ECV is sometimes used before the end of pregnancy (around 34 weeks) but the results might be different when it is used just before childbirth. Also, it might not be possible to turn the unborn baby at this late stage. We wanted to know if using ECV at the end of pregnancy resulted in safer childbirth or was harmful.

\section{What evidence did we find?}

We found 8 studies involving 1308 women. (We included studies up to 28 February 2015.) All the studies were randomised and involved women with low-risk pregnancies. Using ECV around 36 weeks or more increased the chance that babies were born head-first and reduced the risk of having a caesarean section. There were no clear differences in other outcomes such as the risk of babies dying. The quality of the studies and therefore the strength of the evidence was varied.

\section{What does this mean?}

If an unborn baby is lying bottom-down, turning it by ECV just before birth can reduce some of the problems this position can cause. These studies are too small to show if ECV is safe to use in women with low-risk pregnancies, however other types of studies suggest that it is safe. We also do not know if it should be used in high-risk cases, such as mothers who have already had a caesarean section, or who are expecting twins.

A visual summary of some of the results from this review can be found here. 


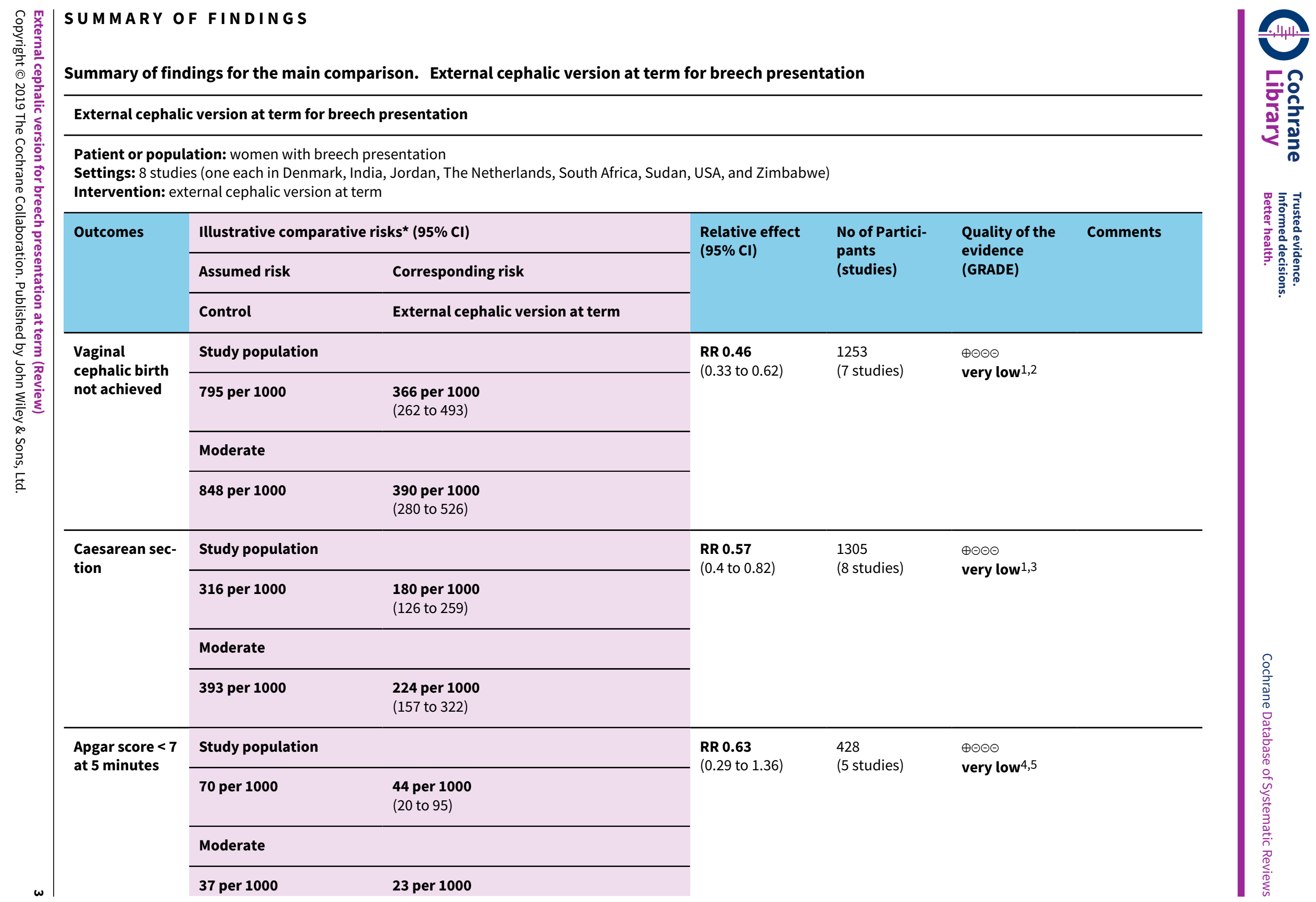




\begin{tabular}{|c|c|c|c|c|c|}
\hline \multirow{5}{*}{ 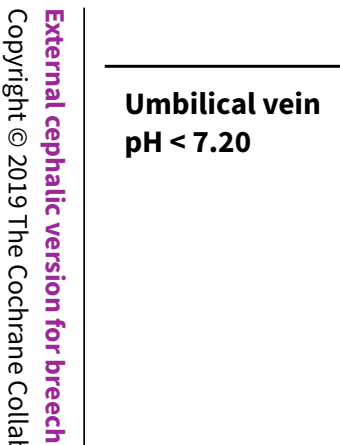 } & \multicolumn{2}{|r|}{ (11 to 50$)$} & \multirow{5}{*}{$\begin{array}{l}\text { RR } \mathbf{0 . 6 5} \\
\text { (0.17 to } 2.44)\end{array}$} & \multirow{5}{*}{$\begin{array}{l}52 \\
\text { (1 study) }\end{array}$} & \multirow{5}{*}{$\begin{array}{l}\oplus \ominus \ominus \ominus \\
\text { very low } 6,7\end{array}$} \\
\hline & \multicolumn{2}{|c|}{ Study population } & & & \\
\hline & 185 per 1000 & $\begin{array}{l}\mathbf{1 2 0} \text { per } \mathbf{1 0 0 0} \\
(31 \text { to } 452)\end{array}$ & & & \\
\hline & \multicolumn{2}{|l|}{ Moderate } & & & \\
\hline & 185 per 1000 & $\begin{array}{l}\mathbf{1 2 0} \text { per } 1000 \\
(31 \text { to } 451)\end{array}$ & & & \\
\hline \multirow{4}{*}{$\begin{array}{l}\text { Neonatal ad- } \\
\text { mission }\end{array}$} & \multicolumn{2}{|c|}{ Study population } & \multirow{4}{*}{$\begin{array}{l}\text { RR } 0.8 \\
(0.48 \text { to } 1.34)\end{array}$} & \multirow{4}{*}{$\begin{array}{l}368 \\
\text { (4 studies) }\end{array}$} & \multirow{4}{*}{$\begin{array}{l}\oplus \ominus \ominus \ominus \\
\text { very low } 4,5\end{array}$} \\
\hline & 151 per 1000 & $\begin{array}{l}\mathbf{1 2 1} \text { per } 1000 \\
\text { (73 to } 203)\end{array}$ & & & \\
\hline & \multicolumn{2}{|l|}{ Moderate } & & & \\
\hline & 146 per 1000 & $\begin{array}{l}\mathbf{1 1 7} \text { per } \mathbf{1 0 0 0} \\
\text { (70 to } 196)\end{array}$ & & & \\
\hline \multirow{4}{*}{$\begin{array}{l}\text { Perinatal } \\
\text { death }\end{array}$} & \multicolumn{2}{|c|}{ Study population } & \multirow{4}{*}{$\begin{array}{l}\text { RR } 0.39 \\
(0.09 \text { to } 1.64)\end{array}$} & \multirow{4}{*}{$\begin{array}{l}1305 \\
\text { (8 studies) }\end{array}$} & \multirow{4}{*}{$\begin{array}{l}\oplus \oplus \ominus \ominus \\
\text { low }^{4,8}\end{array}$} \\
\hline & 9 per 1000 & $\begin{array}{l}4 \text { per } 1000 \\
(1 \text { to } 15)\end{array}$ & & & \\
\hline & \multicolumn{2}{|l|}{ Moderate } & & & \\
\hline & 0 per 1000 & $\begin{array}{l}\text { O per } 1000 \\
(0 \text { to } 0)\end{array}$ & & & \\
\hline
\end{tabular}

${ }^{\star}$ The basis for the assumed risk (e.g. the median control group risk across studies) is provided in footnotes. The corresponding risk (and its $95 \%$ confidence interval) is based on the assumed risk in the comparison group and the relative effect of the intervention (and its $95 \% \mathrm{Cl}$ ).

Cl: Confidence interval; RR: Risk ratio;

GRADE Working Group grades of evidence

High quality: Further research is very unlikely to change our confidence in the estimate of effect.

Moderate quality: Further research is likely to have an important impact on our confidence in the estimate of effect and may change the estimate.

Low quality: Further research is very likely to have an important impact on our confidence in the estimate of effect and is likely to change the estimate.

Very low quality: We are very uncertain about the estimate.

1 Most studies contributing data had design limitations, with more than $40 \%$ of weight from a study with serious design limitations.

2 Statistical heterogeneity $(12>30 \%)$. Variation in size of effect. 
Statistical heterogeneity $(12>30 \%)$. Variation in size and direction of effect.

4 Most studies contributing data had design limitations.

5 Wide confidence interval crossing the line of no effect and few events.

6 One study with design limitations.

Wide confidence interval crossing the line of no effect, few events and small sample size.

8 Wide confidence interval crossing the line of no effect. 


\section{B A C K G R O U N D}

\section{Description of the condition}

Approximately $3 \%$ to $4 \%$ of all pregnant women who reach full term will have a fetus in breech presentation. This may be caused by an underlying fetal or maternal abnormality, or could be an apparently chance occurrence, or related to an otherwise benign variant such as cornual placental position. In the latter instance, breech presentation places a healthy fetus and mother at increased risk of a complicated vaginal delivery or caesarean section.

Breech delivery, whether vaginally or by caesarean section, has a higher incidence of poor perinatal outcomes than cephalic birth. For example, the incidence of minor childhood handicap following breech presentation has been found to be high (19.4\%) and similar for those delivered following trial of labour and those following an elective caesarean section (Danielian 1996).

The majority of women with a breech presenting baby would prefer a vaginal birth although most would choose caesarean section if there is a medical indication (Gamble 2000; Geary 1997; Hildingsson 2002; Turnbull 1999). For the singleton fetus in breech presentation, caesarean section has been shown to be safer for the fetus than vaginal birth in many settings (Hofmeyr 2005), although a large prospective study suggested that vaginal breech delivery may be safe under certain conditions with experienced practitioners (Goffinet 2006).

The risks associated with caesarean section are low, however caesarean section is not without maternal risk and in developed countries remains the largest contributing factor to the incidence of maternal mortality and morbidity following childbirth (Minkoff 2003). A Cochrane review of planned caesarean section versus planned vaginal delivery for breech pregnancy at term, reported that even though $45 \%$ of women in the planned vaginal delivery group were delivered by caesarean section, planned caesarean section was associated with an increase in maternal morbidity (risk ratio (RR) 1.29, 95\% confidence interval $(\mathrm{Cl}) 1.03$ to 1.61 ) (Hofmeyr 2003). Furthermore, although the overall risk is very small, recent estimates of the incidence of mortality associated with elective caesarean section were nearly tripled compared to vaginal birth (Cooper 2002; Hall 1999). In addition to the increase in immediate morbidity following caesarean section, intraabdominal adhesions may occur after caesarean section resulting in subsequent infertility (LaSala 1987). The presence of the uterine scar puts future pregnancies at increased risk of complications such as ectopic pregnancy, placenta previa, accreta and abruption, and uterine rupture (Dashe 2002; Gilliam 2002; Lydon-Rochelle 2001; Minkoff 2003). A further deterrent to caesarean section is that the procedure requires the expertise of an obstetrician or other health worker with surgical training, and limits the role for low-risk obstetrical care providers such as midwives and family practitioners. A review of strategies to reduce caesarean section rates identified external cephalic version (ECV) as the only clinical intervention with demonstrated Level 1 evidence for reducing primary caesarean section rates overall (Walker 2002).

\section{Description of the intervention}

Considering the complications that can arise from breech delivery, it is not surprising that, over the years, the possibility of manipulating the baby from the breech to the cephalic presentation has intrigued obstetric caregivers. ECV is a procedure in which the baby is manipulated by pressure through the mother's abdominal wall into a cephalic (head-down) position.

ECV before term (usually before 34 weeks' gestation) came into routine obstetric practice on the basis of the self-evident immediate effectiveness of the procedure as well as reassuring results from several non-randomised trials, and in spite of the negative results of the only randomised trial reported prior to 1980 (Brosset 1956). The popularity of ECV before term waned after the mid-1970s, partly because of reports of a substantial perinatal mortality associated with the procedure (Bradley-Watson 1975), and the increasing perception of caesarean section as a safer option than ECV or breech delivery.

Prior to the mid-1970s, ECV was usually attempted before term because of the belief that the procedure would seldom be successful at term. Subsequent studies showed that with the use of tocolysis (medication to relax the uterus), ECV could be achieved in a substantial proportion of women with breech presentation at term. ECV at term differs in many fundamental ways from that performed before term. These include the fact that the fetus is mature and may be delivered more readily in the event of complications, and that spontaneous versions without ECV attempt, or reversion after successful ECV, are less common at term. ECV before term is therefore evaluated as a separate procedure (see 'External cephalic version for breech presentation before term' (Hutton 2006)). The current review includes studies in which the intention was to include pregnant women at or near term (i.e. from 36 weeks' gestation).

External cephalic version at term has been shown to be feasible in two small uncontrolled trials in women with previous caesarean section (Flamm 1991; Schachter 1994), and in two in women in labour (Ferguson 1985; Fortunato 1988). El-Muzaini 2008a and El-Muzaini 2008b are abstract reports of prospective controlled studies of ECV in labour and with previous caesarean section respectively, with results in favour of ECV, but it is not clear whether these studies were randomised. To our knowledge, no randomised trials of these interventions have been reported.

Several authors have investigated which factors are associated with an increased chance of successful external cephalic version (Boucher 2003; Fortunato 1988; Guyer 2001; Lau 1997; Le Bret 2004). Factors which have been found to predict failure of ECV attempt include engagement of the presenting part, difficulty in palpating the fetal head and a tense uterus on palpation (Lau 1997), and increased amniotic fluid volume (Boucher 2003). However, a prediction model based on clinical parameters was found to be insufficiently accurate to be useful in predicting the outcome of ECV attempts (Chan 2004).

The majority of women prefer vaginal birth over caesarean birth (Hildingsson 2002). As ECV is the primary intervention to achieve a vaginal delivery when the baby is in breech presentation, it would seem logical that women would be highly motivated to try it. The preferences of women with breech presentation regarding their care appear to have changed over the past couple of decades, and vary by location. In an Israeli study in 1995, 54\% were willing to consider ECV and 65\% preferred planned caesarean section if the breech presentation persisted, compared with $24 \%$ and $97 \%$ respectively in 2001 (Yogev 2002). In an Australian study in $2001,39 \%$ of women attending antenatal clinic would choose ECV 
if needed, and $22 \%$ were undecided (Raynes-Greenow 2004). In another Australian study, Nassar 2007 evaluated a decision aid for women with breech presentation at term. The decision aid was not intended to increase or decrease intervention rates, but rather aim to support informed decision-making that is consistent with personal values. Seventy-four per cent of women who were randomised to receive the decision aid expressed an intention to have ECV if needed, while $66 \%$ of women who received normal care would choose ECV. A higher proportion of women who received the additional information reported that they had enough information to make a decision $(95.7 \%$, compared with $73.6 \%$, at first follow-up). The women who received the decision aid experienced lower decisional conflict, increased knowledge, and greater satisfaction with their decision. Murray-Davis 2012 reported that women participating in a trial comparing the timing of ECV preferred the procedure to be carried out at 34 to 36 weeks' gestation rather than after 37 weeks, as it was perceived to have physiological and practical advantages. However, their sample is likely to have over-estimated preferences for early ECV as that option was only available to trial participants.

Complications reported following ECV at term include fracture of the baby's femur (Papp 2004), prolonged tachycardia (rapid heartbeat) of the baby (Nzewi 1999), sinusoidal baby's heart rate pattern (a fluctuating pattern sometimes indicating compromise) (Ferber 1999), and fetal-maternal haemorrhage (bleeding from the baby's to the mother's circulation in the placenta) (Shankar 2004). The rate of caesarean section during labour has been found to be greater following successful ECV than in spontaneous cephalic presentation: 20\% versus 6.3\%, RR 3.2 (Ben-Haroush 2002); $27.6 \%$ versus $12.5 \%$, RR $2.04 ; 95 \% \mathrm{Cl} 1.43$ to 2.91 (Chan 2004b); odds ratio 2.04 for nulliparous women, 4.30 for multiparous (Vezina 2004). This is not surprising, given that women with persistent breech presentation in the first instance are a high-risk group. Cord blood gases at delivery were no different (Chan 2004c).

However, series of cases have reported very low complication rates with ECV (Boucher 2003; Impey 1999; Impey 2005; Tong 2012). A review of 44 studies of ECV (7377 participants) from 1990 to 2002 found the most frequently reported complication to be transient abnormal baby's heart rate patterns (5.7\%). Less frequent complications were persisting pathological baby's heart rate patterns $(0.37 \%)$; vaginal bleeding $(0.47 \%)$; placental abruption (0.12\%); emergency caesarean section $(0.43 \%)$; and perinatal mortality (0.16\%) (Collaris 2004). Because of the risk of allo-immunisation, anti-D prophylaxis is recommended for nonsensitised D-negative women following ECV attempts (Fung Kee Fung 2003).

Contra-indications to ECV include: multiple pregnancy, severe abnormality, unsatisfactory condition or death of the baby, caesarean section necessary irrespective of the presentation (e.g. major placenta praevia), and ruptured membranes. Relative contraindications include previous caesarean section, poor growth of the baby, and bleeding from the uterus.

The question of whether ECV might increase the risk of motherto-child transmission of viral infections such as HIV is important and, in the absence of direct evidence, we have reviewed the relevant biological evidence and concluded that, unlike fetalmaternal transfusion (bleeding from the baby's to the mother's circulation in the placenta), maternal-fetal transfusion is extremely rare, and unlikely to be precipitated by ECV (Holmes 2004). It is also reassuring that in a randomised trial of fundal pressure to expel the baby during caesarean section, no evidence of maternal-fetal transfusion was found (Owens 2003).

Several authors have reported success rates for ECV at term in routine clinical practice in the region of $40 \%$ to 50\%: 53\% (Hughes 1997); 39\% (Williams 1999); 55\% (Guyer 2001); 45\% (Devendra 2002); 43\% (Lojacono 2003); 51\% (Skupski 2003); $42 \%$ to $65 \%$ (depending on amniotic fluid volume (Boucher 2003)); and 51\% (Le Bret 2004).

Readers are referred to previous reviews of the topic (Hofmeyr 1989; Hofmeyr 1991; Hofmeyr 1992; Hofmeyr 1993; Zhang 1993). See also related Cochrane systematic reviews: 'External cephalic version for breech presentation before term', 'Cephalic version by postural management for breech presentation' and 'Interventions for helping to turn term breech babies to head first presentation when using external cephalic version.' (Hutton 2006; Hofmeyr 2000; Cluver 2012).

\section{Why it is important to do this review}

There is a higher risk of complications when delivering a baby presenting in the breech rather than in the cephalic position. Caesarean section appears to be safer for the baby, but presents a higher level of maternal morbidity. Achieving a cephalic vaginal delivery by successfully rotating the baby in utero therefore, potentially offers a way to reduce the caesarean section rate, and improve perinatal and maternal outcomes. It may be of particular importance in resource-poor situations in which women may be unable to reach health services during labour, and caesarean sections are unavailable or unsafe (Hofmeyr 2004).

\section{O B JECTIVES}

To assess, using the best available evidence, the effects of external cephalic version (ECV) at or near term for breech presentation on: presentation at and method of delivery; and perinatal and maternal morbidity and mortality.

\section{METHODS}

\section{Criteria for considering studies for this review}

\section{Types of studies}

Clinical trials comparing the effects of external cephalic version (ECV) at or near term, with or without tocolysis, with a control group (no ECV attempt). Cluster-randomised studies and cross-over studies were eligible for inclusion, as mentioned in Unit of analysis issues. Quasi-randomised controlled trials were not eligible for inclusion.

\section{Types of participants}

Pregnant women with babies in the breech presentation at or near term and no contraindications to ECV.

\section{Types of interventions}

ECV attempt at term, with or without the use of tocolysis, compared with no ECV attempt.

\section{Types of outcome measures}

Outcomes were included if: 
- they were determined to be clinically meaningful;

- reasonable measures were taken to minimise observer bias;

- missing data were insufficient to materially influence conclusions;

- data were available for analysis according to original allocation, irrespective of protocol violations;

- and data were available in a format suitable for analysis.

\section{Primary outcomes}

1. Vaginal cephalic birth not achieved (not prespecified)

2. Caesarean section

\section{Secondary outcomes}

1. Non cephalic presentation at delivery

2. Vaginal breech birth (not prespecified)

3. Apgar score less than seven at one minute (not prespecified)

4. Apgar score less than seven at five minutes

5. Umbilical vessel $\mathrm{pH}$ below 7.2

6. Perinatal death

7. Neonatal admission

8. Enrolment-delivery interval (not prespecified)

\section{Search methods for identification of studies}

The following methods section of this review is based on a standard template used by the Cochrane Pregnancy and Childbirth Group.

\section{Electronic searches}

We searched the Cochrane Pregnancy and Childbirth Group's Trials Register by contacting the Trials Search Co-ordinator (28 February 2015).

The Cochrane Pregnancy and Childbirth Group's Trials Register is maintained by the Trials Search Co-ordinator and contains trials identified from:

1. monthly searches of the Cochrane Central Register of Controlled Trials (CENTRAL);

2. weekly searches of MEDLINE (Ovid);

3. weekly searches of Embase (Ovid);

4. monthly searches of CINAHL (EBSCO);

5. handsearches of 30 journals and the proceedings of major conferences;

6. weekly current awareness alerts for a further 44 journals plus monthly BioMed Central email alerts.

Details of the search strategies for CENTRAL, MEDLINE, Embase and CINAHL, the list of handsearched journals and conference proceedings, and the list of journals reviewed via the current awareness service can be found in the 'Specialized Register' section within the editorial information about the Cochrane Pregnancy and Childbirth Group.

Trials identified through the searching activities described above are each assigned to a review topic (or topics). The Trials Search Coordinator searches the register for each review using the topic list rather than keywords.
[For details of additional searches we carried out for the previous version of this review (Hofmeyr 2012), see Appendix 1.]

\section{Searching other resources}

We searched the reference lists of retrieved studies.

We did not apply any language or date restrictions.

\section{Data collection and analysis}

For methods used when assessing the trials identified in the previous version of this review (see Hofmeyr 2012). For this update, the following methods were used for assessing the trial identified by the updated search (Rita 2012).

\section{Selection of studies}

Two review authors independently assessed for inclusion all the potential studies identified as a result of the search strategy. We resolved any disagreement through discussion and, if required, would have consulted a third assessor.

\section{Data extraction and management}

We designed a form to extract data. For eligible studies, two review authors extracted the data using the agreed form. We entered data into Review Manager software (RevMan 2014) and checked for accuracy.

When information was unclear, we attempted to contact authors of the original reports to provide further details.

\section{Assessment of risk of bias in included studies}

Two review authors independently assessed the risk of bias for each study using the criteria outlined in the Cochrane Handbook for Systematic Reviews of Interventions (Higgins 2011). We resolved any disagreement through discussion and, if required, would have consulted R Kulier.

\section{(1) Random sequence generation (checking for possible selection bias)}

We described for each included study the method used to generate the allocation sequence in sufficient detail to allow an assessment of whether it should produce comparable groups.

We assessed the method as:

- low risk of bias (any truly random process, e.g. random number table; computer random number generator);

- high risk of bias (any non-random process, e.g. odd or even date of birth; hospital or clinic record number);

- unclear risk of bias.

\section{(2) Allocation concealment (checking for possible selection bias)}

We described for each included study the method used to conceal allocation to interventions prior to assignment and assessed whether intervention allocation could have been foreseen in advance of, or during recruitment, or changed after assignment.

We assessed the methods as:

- low risk of bias (e.g. telephone or central randomisation; consecutively numbered sealed opaque envelopes); 
- high risk of bias (open random allocation; unsealed or nonopaque envelopes, alternation; date of birth);

- unclear risk of bias.

\section{(3.1) Blinding of participants and personnel (checking for possible performance bias)}

We described for each included study the methods used, if any, to blind study participants and personnel from knowledge of which intervention a participant received. We considered that studies were at low risk of bias if they were blinded, or if we judged that the lack of blinding unlikely to affect results. We assessed blinding separately for different outcomes or classes of outcomes.

We assessed the methods as:

- low, high or unclear risk of bias for participants;

- low, high or unclear risk of bias for personnel.

\section{(3.2) Blinding of outcome assessment (checking for possible detection bias)}

We described for each included study the methods used, if any, to blind outcome assessors from knowledge of which intervention a participant received. We assessed blinding separately for different outcomes or classes of outcomes.

We have assessed methods used to blind outcome assessment as:

- low, high or unclear risk of bias.

\section{(4) Incomplete outcome data (checking for possible attrition bias due to the amount, nature and handling of incomplete outcome data)}

We described for each included study, and for each outcome or class of outcomes, the completeness of data including attrition and exclusions from the analysis. We stated whether attrition and exclusions were reported and the numbers included in the analysis at each stage (compared with the total randomised participants), reasons for attrition or exclusion where reported, and whether missing data were balanced across groups or were related to outcomes. Where sufficient information was reported, or could be supplied by the trial authors, we planned to re-include missing data in the analyses which we undertook.

We assessed methods as:

- low risk of bias (e.g. no missing outcome data; missing outcome data balanced across groups);

- high risk of bias (e.g. numbers or reasons for missing data imbalanced across groups; 'as treated' analysis done with substantial departure of intervention received from that assigned at randomisation);

- unclear risk of bias.

\section{(5) Selective reporting (checking for reporting bias)}

We described for each included study how we investigated the possibility of selective outcome reporting bias and what we found.

We assessed the methods as:
- low risk of bias (where it is clear that all of the study's prespecified outcomes and all expected outcomes of interest to the review have been reported);

- high risk of bias (where not all the study's prespecified outcomes have been reported; one or more reported primary outcomes were not prespecified; outcomes of interest are reported incompletely and so cannot be used; study fails to include results of a key outcome that would have been expected to have been reported);

- unclear risk of bias.

(6) Other bias (checking for bias due to problems not covered by (1) to (5) above)

We described for each included study any important concerns we had about other possible sources of bias.

\section{(7) Overall risk of bias}

We made explicit judgements about whether studies were at high risk of bias, according to the criteria given in the Handbook (Higgins 2011). With reference to (1) to (6) above, we planned to assess the likely magnitude and direction of the bias and whether we considered it is likely to impact on the findings. In future updates, we will explore the impact of the level of bias through undertaking sensitivity analyses - see Sensitivity analysis.

For this update the quality of the evidence was assessed using the GRADE approach (Schunemann 2009) in order to assess the quality of the body of evidence relating to the following outcomes for the main comparisons.

1. Vaginal cephalic birth not achieved

2. Caesarean section

3. Apgar score less than seven at five minutes

4. Umbilical $\mathrm{pH}$ below 7.2

5. Perinatal death

6. Neonatal admission

The GRADE profiler (Grade 2008) was used to import data from Review Manager 5.3 (RevMan 2014) in order to create a'Summary of findings' table. A summary of the intervention effect and a measure of quality for each of the above outcomes was produced using the GRADE approach. The GRADE approach uses five considerations (study limitations, consistency of effect, imprecision, indirectness and publication bias) to assess the quality of the body of evidence for each outcome. The evidence can be downgraded from 'high quality' by one level for serious (or by two levels for very serious) limitations, depending on assessments for risk of bias, indirectness of evidence, serious inconsistency, imprecision of effect estimates or potential publication bias.

\section{Measures of treatment effect}

\section{Dichotomous data}

For dichotomous data, we present results as summary risk ratio with $95 \%$ confidence intervals.

\section{Continuous dato}

For continuous data, we used the mean difference if outcomes were measured in the same way between trials. We planned to use the 
standardised mean difference to combine trials that measured the same outcome, but used different methods, if required.

\section{Unit of analysis issues}

\section{Cluster-randomised trials}

We would have included cluster-randomised trials in the analyses along with individually-randomised trials had there been any. We would have adjusted their sample sizes or standard errors using the methods described in the Handbook in Section 16.3.4 and 16.3.6 (Higgins 2011) using an estimate of the intracluster correlation coefficient (ICC) derived from the trial (if possible), from a similar trial or from a study of a similar population. In future updates of the review, if we use ICCs from other sources, we will report this and conduct sensitivity analyses to investigate the effect of variation in the ICC. Had we identified both cluster-randomised trials and individually-randomised trials, we planned to synthesise the relevant information. We would consider it reasonable to combine the results from both if there was little heterogeneity between the study designs and the interaction between the effect of intervention and the choice of randomisation unit was considered to be unlikely.

We would also acknowledge heterogeneity in the randomisation unit and perform a sensitivity or subgroup analysis to investigate the effects of the randomisation unit.

\section{Cross-over trials}

We identified no cross-over trials on this topic for the update, but if such trials were identified and deemed eligible for inclusion, we would include them in the analyses with parallel group trials, using methods described by Elbourne 2002.

\section{Dealing with missing data}

For included studies, we noted levels of attrition. We explored the impact of including studies with high levels of missing data in the overall assessment of treatment effect by using sensitivity analysis.

For all outcomes we have carried out analyses, as far as possible, on an intention-to-treat basis, i.e. we attempted to include all participants randomised to each group in the analyses. The denominator for each outcome in each trial was the number randomised minus any participants whose outcomes were known to be missing.

\section{Assessment of heterogeneity}

We assessed statistical heterogeneity in each meta-analysis using the $\mathrm{Tau}^{2}, \mathrm{I}^{2}$ and $\mathrm{Chi}^{2}$ statistics. We regarded heterogeneity as substantial if an $\mathrm{I}^{2}$ was greater than $30 \%$ and either a $\mathrm{Tau}^{2}$ was greater than zero, or there was a low $\mathrm{P}$ value (less than 0.10) in the $\mathrm{Chi}^{2}$ test for heterogeneity. Had we identified substantial heterogeneity (above $30 \%$ ), we planned to explore it by prespecified subgroup analysis.

\section{Assessment of reporting biases}

Where we suspected reporting bias (see 'Selective reporting bias' above), we attempted to contact study authors, asking them to provide missing outcome data. Where this was not possible, and the missing data were thought to introduce serious bias, we explored the impact of including such studies in the overall assessment of results by a sensitivity analysis.
In future updates, if there are 10 or more studies in the metaanalysis we will investigate reporting biases (such as publication bias) using funnel plots. We will assess funnel plot asymmetry visually. If asymmetry is suggested by a visual assessment, we will perform exploratory analyses to investigate it.

\section{Data synthesis}

We carried out statistical analysis using the Review Manager software (RevMan 2014). We used fixed-effect meta-analysis for combining data where trials were examining the same intervention, and the trials' populations and methods were judged sufficiently similar.

If there was clinical heterogeneity sufficient to expect that the underlying treatment effects differed between trials, or if substantial statistical heterogeneity was detected, we used random-effects meta-analysis to produce an overall summary, if an average treatment effect across trials was considered clinically meaningful. The random-effects summary was treated as the average of the range of possible treatment effects and we discussed the clinical implications of treatment effects differing between trials. If the average treatment effect was not clinically meaningful, we would not have combined trials. Where we used random-effects analyses, the results were presented as the average treatment effect with $95 \%$ confidence intervals, and the estimates of $\mathrm{Tau}^{2}$ and $1^{2}$.

\section{Subgroup analysis and investigation of heterogeneity}

We did not perform any subgroup analyses in the original review or this update (2015). If we identified substantial heterogeneity in a fixed-effect meta-analysis, we noted this and repeated the analysis using a random-effects method. In future updates, if sufficient data become available, we will conduct the following subgroup analyses on primary outcomes.

1. Nulliparous women versus multiparous women versus parity mixed or not stated.

2. Frank breech presentation versus non-frank breech presentation versus presentation mixed or not stated

3. Studies recruiting mainly black African women versus studies recruiting mainly Caucasian women versus other studies.

We will assess subgroup differences by interaction tests available within RevMan (RevMan 2014) and report the results of subgroup analyses quoting the $\mathrm{Chi}^{2}$ statistic and $\mathrm{P}$ value, and the interaction test $I^{2}$ value.

\section{Sensitivity analysis}

Due to the potentially high risk of bias in three of the studies (Brocks 1984; Dafallah 2004; Hindawi 2005) and our lack of success in contacting the latter two trial authors, we undertook the metaanalyses of included studies twice: first, including all the studies and second, excluding the studies at high risk of bias. When sensitivity analyses showed that the overall results and conclusions from primary outcomes were not affected by their inclusion, we regarded the results of the review with a higher degree of certainty. If both or either of these studies had greatly influenced the findings of the review, we would have recommended an appropriate degree of caution. 
It has been suggested that ECV may be more successful (and spontaneous version more common) in black African than Caucasian women, possibly because of the tendency for the presenting part to remain high until the onset of labour (Hofmeyr 1986). Ethnicity was not a pre-defined subgroup analysis for the original review. However for this update (2015), post-hoc sensitivity analysis excluding the three studies in black African women (Dafallah 2004; Hofmeyr 1983; Mahomed 1991) was conducted.

\section{RE S U L T S}

\section{Description of studies}

\section{Results of the search}

Eight studies were included in the review (one from an updated search: Rita 2012).

\section{Included studies}

See Characteristics of included studies.

\section{Design}

All eight studies were two-arm randomised controlled trials, in which women were randomised to either receive attempted ECV or no attempt at ECV.

\section{Sample sizes}

The total number of women included in the eight included studies was 1308. Five of the studies included 65 or fewer women (Brocks 1984; Hofmeyr 1983; Rita 2012; Van de Pavert 1990; Van Dorsten 1981), two recruited around 200 women (Hindawi 2005; Mahomed 1991), and one included over 600 women (Dafallah 2004).

\section{Setting}

Studies were carried out in Denmark, India, Jordan, the Netherlands, South Africa, Sudan, the USA and Zimbabwe. The recruitment and any intervention happened in an outpatient clinic in Brocks 1984; Dafallah 2004; Hindawi 2005; Van Dorsten 1981, women in Hofmeyr 1983 were recruited when admitted to hospital from antenatal clinics and subsequently referred back to the antenatal clinic, and the setting was not described in the other studies (Mahomed 1991; Rita 2012; Van de Pavert 1990).

\section{Participants}

Pregnant women with a breech presentation baby were included in all studies. Women were recruited during the 37 th week of pregnancy (Brocks 1984), 36 to 38 weeks' gestation (Dafallah 2004), from 37 weeks' gestation (Hindawi 2005; Mahomed 1991; Rita 2012) after 36 weeks' gestation (Hofmeyr 1983; Van de Pavert 1990), and 37 to 39 weeks' gestation (Van Dorsten 1981). Several reports explicitly stated that only women with singleton pregnancies were eligible (Brocks 1984; Hindawi 2005; Mahomed 1991; Rita 2012). The women included in these studies had low-risk pregnancies and medical histories, with no contra-indications to vaginal delivery or external version. Women with a previous caesarean section or uterine scar were excluded from all studies except Rita 2012, which excluded those with two or more previous caesarean sections.

\section{Interventions}

A variety of different techniques and maternal positions were used to perform ECV (classic forward roll technique (Dafallah 2004, Van de Pavert 1990), forward roll or back flip (Hofmeyr 1983; Mahomed 1991; Van Dorsten 1981), woman lying in left lateral tilt (Brocks 1984; Rita 2012), in the Trendelberg position (Dafallah 2004). lying with left or right lateral tilt (Hofmeyr 1983). An ultrasound scan confirming breech presentation was carried out prior to ECV in all studies (Brocks 1984; Dafallah 2004; Hindawi 2005; Hofmeyr 1983; Mahomed 1991; Rita 2012; Van de Pavert 1990; Van Dorsten 1981), and a reactive non-stress test/unstressed cardiotocogram was often recorded (Brocks 1984; Mahomed 1991; Van de Pavert 1990; Van Dorsten 1981).

A single attempt at ECV was carried out in Brocks 1984; Hindawi 2005; Mahomed 1991; and Rita 2012. Repeat attempts were allowed in Dafallah 2004 (up to three attempts), Hofmeyr 1983 and Van Dorsten 1981 (in the opposite direction to the initial attempt if it failed), and in Van de Pavert 1990 if the first attempt without tocolysis was unsuccessful, ritodrine was administered and ECV was attempted again.

No analgesia was used in these studies. This review included trials with and without tocolysis. Four trials used tocolysis routinely for ECV (ritodrine: Brocks 1984 and Hindawi 2005; hexaprenaline: Mahomed 1991; terbutaline sulphate: Van Dorsten 1981). In two trials, tocolysis was used if the initial ECV attempt was unsuccessful (hexaprenaline: Hofmeyr 1983; ritodrine: Van de Pavert 1990). No tocolysis was used in Dafallah 2004 and Rita 2012.

\section{Outcomes}

All studies reported caesarean section and perinatal death. Outcomes regarding presentation at delivery were not reported in a consistent way, however in most reports the information was available to impute the outcomes of interest (e.g. vaginal cephalic birth not achieved by adding caesarean section and breech vaginal delivery).

\section{Excluded studies}

Six studies identified by the search strategy were excluded from this review (see Characteristics of excluded studies). They were excluded because group allocation was not randomised (Besio 1994; El-Muzaini 2008a; El-Muzaini 2008b; Stine 1985), compared early with late ECV (Rust 2005), and ECV attempts started at 33 weeks' gestation (Van Veelen 1989).

\section{Risk of bias in included studies}

See Characteristics of included studies, Figure 1 and Figure 2. 
Figure 1. 'Risk of bias' graph: review authors' judgements about each risk of bias item presented as percentages across all included studies

Random sequence generation (selection bias)

Allocation concealment (selection bias)

Blinding of participants and personnel (performance bias)

Blinding of outcome assessment (detection bias)

Incomplete outcome data (attrition bias)

Selective reporting (reporting bias)

Other bias
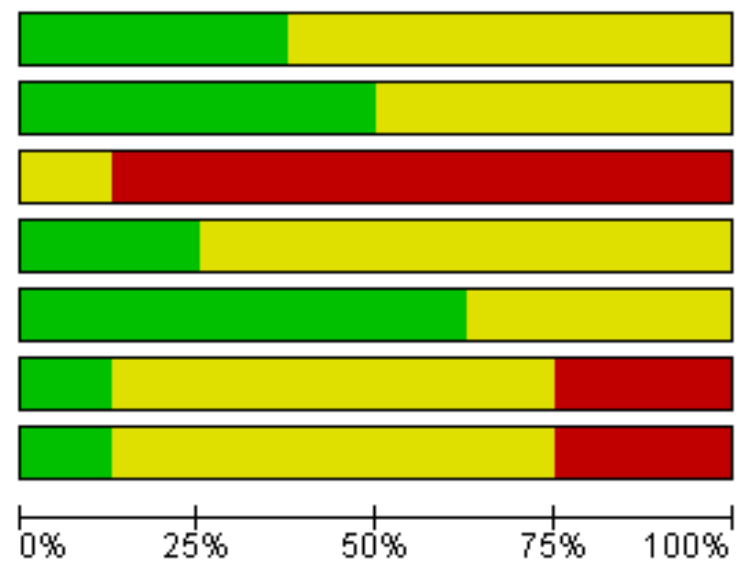

Low risk of bias

Unclear risk of bias

High risk of bias 
Figure 2. 'Risk of bias' summary: review authors' judgements about each risk of bias item for each included study.

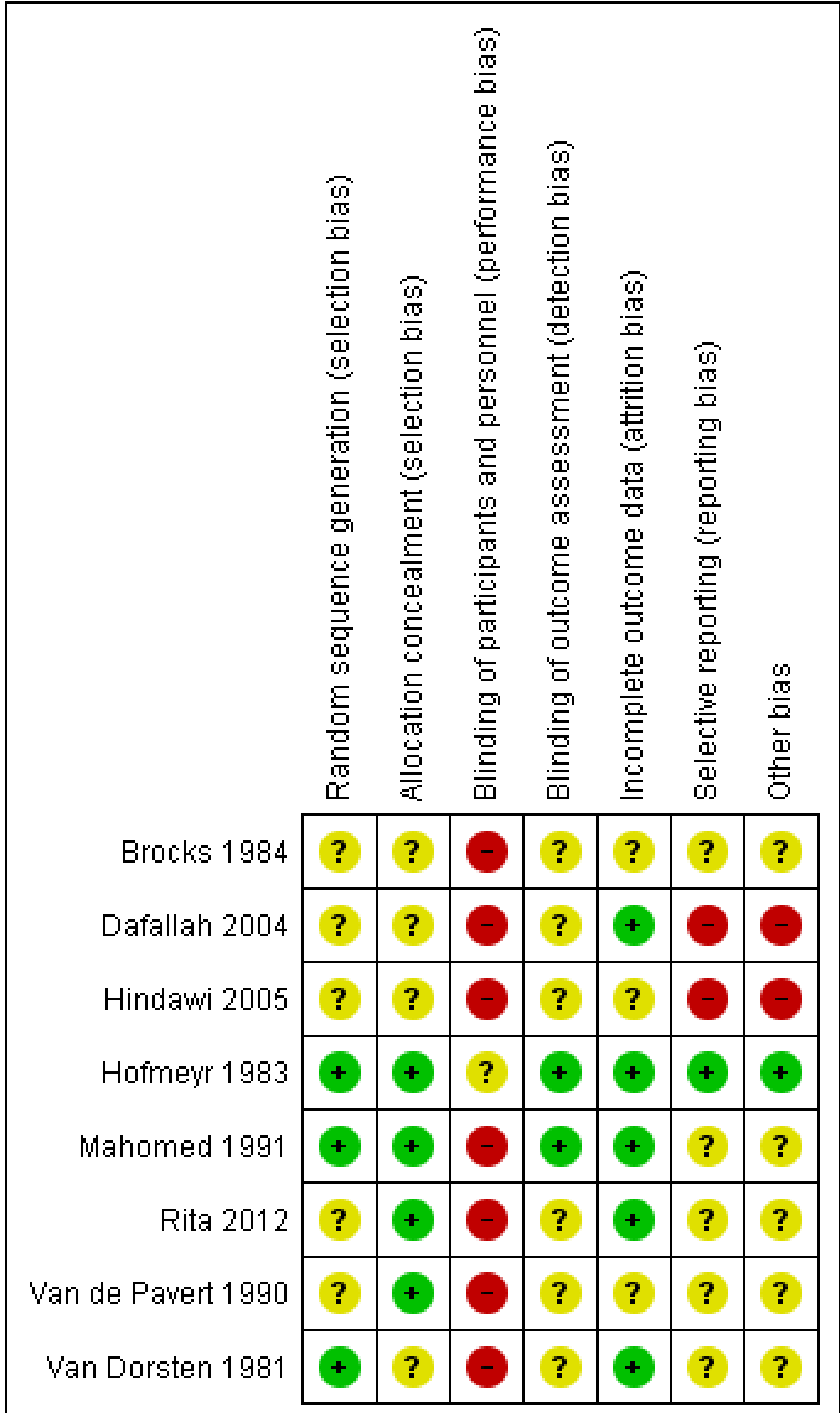

\section{Allocation}

In four trials, randomly ordered sealed envelopes or cards were used for allocation (Hofmeyr 1983; Mahomed 1991; Rita 2012; Van de Pavert 1990), but only two (Mahomed 1991; Rita 2012) specified that the cards were sequentially numbered. Van Dorsten 1981 used a random number table and Brocks 1984 used 'random' allocation without specifying the mechanism. Concealment of allocation was thus not optimal. 
Dafallah 2004 and Hindawi 2005 did not describe the methods of randomisation and allocation concealment at all. Attempts to contact the respective authors for more information failed. See Sensitivity analysis.

\section{Blinding}

Due to the nature of the intervention, no studies attempted to blind participants or clinicians to group allocation. Women would have been aware of the intervention and this may have affected decisions regarding care in later pregnancy and at the birth. Staff would be aware of the intervention and this may have affected other aspects of care and decision-making at the birth. This may have had an impact on outcomes such as caesarean section. In one study (Van de Pavert 1990), it was much more likely that women would have a caesarean section if external cephalic version (ECV) had been attempted and failed than in women where ECV had never been attempted, so it is possible than attempt and failure of ECV affects decision-making about caesarean section.

One study (Mahomed 1991) described blinding assessors to some outcomes (Apgar scores, admission to neonatal unit, stillbirth, neonatal death). In one study (Hofmeyr 1983), outcome assessment was from records (it was not clear whether attempted ECV or randomisation group was stated in the records). It states that "there was no subsequent intervention in their management by the investigator". In all other studies, it was not clear whether outcome assessment was carried out by staff who were involved in women's care. It is unlikely that lack of blinding of outcome assessors could have influenced most of the outcomes measured, but assessment of the infant may have been affected by knowledge of randomisation group.

\section{Incomplete outcome data}

Brocks 1984 studied 65 women who agreed to randomisation and a further 65 who either specifically requested or refused an ECV attempt. Since factors that may have a bearing on the outcome of pregnancy may influence the decision to accept ECV, we have limited this review to an analysis of the 65 randomised cases. Hindawi 2005 gives no explanation for the large difference in group size (90 versus 102).

The exclusion of three women after enrolment in Van Dorsten 1981 is unlikely to have affected the results materially. Van de Pavert 1990 attempted ECV without tocolysis in $21 / 25$ of the study group, and with tocolysis in $16 / 20$ initial failures. Thus $8 / 25(32 \%)$ received no ECV attempt (4) or incomplete ECV protocol (4). ECV was attempted on request in $5 / 27$ of the control group, tocolysis being used in the three which were successful. While the analysis was appropriate according to intention-to-treat, the rate of non-compliance with the allocated treatment reduces the power of the study to detect differences resulting from ECV attempt.

\section{Selective reporting}

Neonatal outcomes were given according to presentation not allocation in Brocks 1984, so were not included in this review. Dafallah 2004 did not report on all prespecified outcomes, e.g. Apgar scores, or other key outcomes of interest, e.g. morbidity. In Hindawi 2005, outcomes are not clearly prespecified. Studies were generally assessed from published reports, without access to the protocols, so it was unclear whether all prespecified outcomes had been reported (Brocks 1984; Mahomed 1991; Rita 2012; Van de Pavert 1990; Van Dorsten 1981).

\section{Other potential sources of bias}

In two trials, higher numbers of women in the ECV group had fundal placentas (Mahomed 1991; Rita 2012), however the clinical implications are unclear.

Group sizes differ by $13 \%$ and outcomes are not clearly prespecified in Hindawi 2005.

Overall, all studies had some design limitations. It was judged that three studies had serious design limitations and were at high risk of bias (Brocks 1984; Dafallah 2004; Hindawi 2005). A sensitivity analysis was carried out to assess the effect of these limitations on the results.

\section{Effects of interventions}

See: Summary of findings for the main comparison External cephalic version at term for breech presentation

\section{External cephalic version at term versus no ECV attempt}

There was significant heterogeneity in the results for the outcomes vaginal cephalic birth not achieved, caesarean section, noncephalic presentation at birth, vaginal breech birth, and Apgar score less than seven at one minute, therefore these were pooled using the random-effects model. For all other data we used the fixed-effect model.

\section{Primary outcomes: Vaginal cephalic birth not achieved and caesarean section}

Overall, the pooled data from included studies show a statistically significant and clinically meaningful reduction in vaginal cephalic birth not being achieved (average risk ratio (RR) 0.46, 95\% confidence interval $(\mathrm{Cl}) 0.33$ to 0.62 , seven trials, 1253 women, evidence graded very low, Analysis 1.1), and caesarean section (average RR $0.57,95 \% \mathrm{Cl} 0.40$ to 0.82 , eight trials, 1305 women, evidence graded very low, Analysis 1.2) when ECV was attempted.

\section{Secondary outcomes: Perinatal and maternal morbidity and mortality}

The pooled data from included studies show a statistically significant and clinically meaningful reduction in non-cephalic presentation at birth (average RR $0.42,95 \% \mathrm{Cl} 0.29$ to 0.61 , eight trials, 1305 women, Analysis 1.3), and vaginal breech delivery (not prespecified, average RR $0.35,95 \% \mathrm{Cl} 0.24$ to 0.50 , seven trials, 685 women, Analysis 1.4).

Data were not available from all the trials for the remaining outcomes. There were no significant differences in the incidence of Apgar score ratings below seven at one minute (not prespecified, random-effects model: average RR $0.67,95 \% \mathrm{Cl} 0.32$ to 1.37 ; three trials, 168 infants, Analysis 1.5) or five minutes (RR 0.63, 95\% Cl 0.29 to 1.36 , five trials, 428 infants, evidence graded very low, Analysis 1.6), low umbilical vein $\mathrm{pH}$ levels (RR $0.65,95 \% \mathrm{Cl} 0.17$ to 2.44 , one trial, 52 infants, evidence graded very low, Analysis 1.7), neonatal admission (RR $0.80,95 \% \mathrm{Cl} 0.48$ to 1.34 , four trials, 368 infants, evidence graded very low, Analysis 1.9), perinatal death (RR 0.39, $95 \% \mathrm{Cl} 0.09$ to 1.64 , eight trials, 1305 infants, evidence graded low, Analysis 1.8), nor time from enrolment to delivery (not prespecified, 
mean difference -0.25 days, $95 \% \mathrm{Cl}-2.81$ to 2.31 , two trials, 256 women, Analysis 1.10).

\section{Sensitivity analyses}

Three studies were judged to have serious design limitations and were at high risk of bias (Brocks 1984; Dafallah 2004; Hindawi 2005). However, a sensitivity analysis excluding these studies from the analyses showed that the overall results were not greatly influenced by their inclusion (random-effect model) (vaginal cephalic birth not being achieved: average RR 0.32, 95\% $\mathrm{Cl} 0.25$ to 0.41 , four trials, 376 women, Analysis 2.1; caesarean section: average RR $0.46,95 \% \mathrm{Cl} 0.27$ to 0.79 , five trials, 428 women, Analysis 2.2; non-cephalic presentation at birth: average RR 0.29, $95 \% \mathrm{Cl} 0.12$ to 0.68 , five trials, 428 women, Analysis 2.3; and vaginal breech delivery: average RR $0.38,95 \% \mathrm{Cl} 0.21$ to 0.69 , five trials, 428 women, Analysis 2.4).

It has been suggested that ECV may be more successful (and spontaneous version more common) in black African than Caucasian women, possibly because of the tendency for the presenting part to remain high until the onset of labour (Hofmeyr 1986). Ethnicity was not a pre-defined subgroup analysis for the original review. However, post-hoc sensitivity analysis excluding the three studies in black African women (Dafallah 2004; Hofmeyr 1983; Mahomed 1991) produced the following results (fixed-effect model): vaginal cephalic birth not achieved: RR $0.49,95 \% \mathrm{Cl} 0.41$ to $0.58,4$ trials, 365 women, Analysis 3.1 ; caesarean section: RR $0.57,95 \% \mathrm{Cl} 0.45$ to 0.73 , five trials, 417 women, Analysis 3.2, noncephalic presentation at birth: RR $0.46,95 \% \mathrm{Cl} 0.39$ to 0.55 , five trials, 417 women Analysis 3.3; vaginal breech birth: RR 0.38, 95\% $\mathrm{Cl} 0.27$ to 0.54 , five trials, 417 women, Analysis 3.4.

\section{DISCUSSION}

\section{Summary of main results}

The evidence from randomised trials shows that attempting external cephalic version at term increases the chance of vaginal cephalic birth, and reduces the chance of caesarean section and vaginal breech delivery. There is not enough evidence from randomised trials to assess complications of external cephalic version at term, however large observational studies suggest that complications are rare (Boucher 2003; Impey 1999; Impey 2005).

\section{Overall completeness and applicability of evidence}

The absolute numbers of non-cephalic births and caesarean sections vary considerably between trials. This probably reflects differences in study populations and caesarean section policies. The direction of effects is, however, consistent, with the exception of the rates of caesarean section in the study of Van de Pavert 1990. Considerable cross-over between groups in the latter study may have reduced the power of the study to show differences related to external cephalic version (ECV). The study authors suggest that against a background of low caesarean section rates for breech presentation, the negative experience of failed ECV may render the woman or doctors more likely to opt for caesarean section.

The women included in these studies had low-risk pregnancies and medical histories. Women with previous caesarean sections were excluded, for example. This limits the applicability of the evidence to other populations of women.
The recent trend to routine caesarean section for persistent breech presentation may result in a greater impact of ECV on caesarean section rates than was apparent in the studies reviewed.

The trials reviewed do not give information on women's views.

No analgesia was used in these studies. This review included trials with and without tocolysis. Four trials used tocolysis routinely for ECV (ritodrine: Brocks 1984 and Hindawi 2005, hexaprenaline: Mahomed 1991, terbutaline sulphate: Van Dorsten 1981). In two trials tocolysis was used if the initial ECV attempt was unsuccessful (hexaprenaline: Hofmeyr 1983, ritodrine: Van de Pavert 1990). No tocolysis was used in Dafallah 2004 and Rita 2012. The use of tocolytic drugs and other interventions to help ECV is covered by a separate Cochrane review (Cluver 2012).

\section{Quality of the evidence}

All of the trials included in this review had design limitations. Due to the nature of the intervention, no studies attempted to blind participants or clinicians to group allocation. Women would have been aware of the intervention and this may have affected decisions regarding care in later pregnancy and at the birth. Staff would be aware of intervention and this may have affected other aspects of care and decision-making at the birth. This may have had an impact on outcomes such as caesarean section. In one study (Van de Pavert 1990), it was much more likely that women would have a caesarean section if ECV had been attempted and failed than in women where ECV had never been attempted, so it is possible than attempt and failure of ECV affects decision-making about caesarean section.

The descriptions of randomisation and allocation procedures were not optimal in several studies (Brocks 1984; Dafallah 2004; Hindawi 2005; Rita 2012; Van de Pavert 1990; Van Dorsten 1981). It is unclear whether this is due to omissions in the reporting of the studies, or limitations of study design.

The level of evidence was graded low (perinatal death) or very low (vaginal cephalic birth not achieved, caesarean section, Apgar score $<7$ at five minutes, umbilical vein $\mathrm{pH}<7.20$, neonatal admission) (Summary of findings for the main comparison). The two graded outcomes addressing mode of delivery (vaginal cephalic birth not achieved, caesarean section) were downgraded for quality of evidence due to design limitations in the studies, and inconsistency due to statistical heterogeneity. The four graded outcomes addressing perinatal outcomes (Apgar score $<7$ at five minutes, umbilical vein $\mathrm{pH}<7.20$, neonatal admission, perinatal death) were downgraded for quality evidence due to design limitations in the studies, and imprecision due to wide confidence intervals and few events.

\section{Potential biases in the review process}

The assessment of risk of bias involves subjective judgements. This potential limitation is minimised by following the procedures in the Cochrane Handbook for Systematic Reviews of Interventions (Higgins 2011), with review authors independently assessing studies and resolving any disagreement through discussion, and if required involving a third assessor in the decision. 


\section{Agreements and disagreements with other studies or reviews}

No recent systematic reviews of randomised trials were found. A systematic review of cohort studies (three) and case-control studies (eight), found an increased caesarean delivery rate for women with a successful external cephalic version (21\%; odds ratio $2.2,95 \%$ confidence interval 1.6 to 3.0) (De Hundt 2014).

\section{AUTHORS' CONCLUSIONS}

\section{Implications for practice}

The studies in this review provide convincing evidence that the chance of breech birth and caesarean section may be substantially reduced by attempting external cephalic version (ECV) at or near term. The numbers studied are too small to give an accurate assessment of the risks of ECV, though data from observation studies are reassuring. There is sound reason for the clinical use of ECV at term, with the appropriate precautions, in any woman in whom the value of an improved chance of a cephalic birth outweighs the risk of the procedure.

\section{Implications for research}

Future research should be directed towards refining the selection of women suitable for ECV attempt at term. For example, previous caesarean section has been regarded as a contraindication to ECV. In an uncontrolled series, ECV was found to be successful in $82 \%$ of 56 women with one or two previous caesarean sections (Flamm 1991).

The place of ECV during labour requires further study. This procedure was reported to be successful in $11(73 \%)$ out of 15 women in labour considered unsuitable for vaginal breech delivery. Caesarean section was avoided in 10 (67\%) of the women (Ferguson 1985).

Further research is needed to define more accurately the effect of ECV on perinatal outcome, and the place of ECV in non-longitudinal lies.

Future studies should include an assessment of women's views.

\section{ACKNOWLEDGEMENTS}

In this update: Therese Dowswell for assessing the blinding of outcome assessors in included studies, Leanne Jones and Denise Atherton for editorial and administrative support, Lynn Hampson for the literature search.

In previous versions: Tess Lawrie for assistance with study selection, data extraction and help preparing this update; Sonja Henderson and Denise Atherton for administrative support; Lynn Hampson and Jill Hampson for the literature search.

Helen West's work is supported by the NIHR Cochrane Programme Grant Project: 13/89/05 - Pregnancy and childbirth systematic reviews to support clinical guidelines.

This project was supported by the National Institute for Health Research, via Cochrane Infrastructure and Cochrane Programme Grant funding to Cochrane Pregnancy and Childbirth. The views and opinions expressed therein are those of the authors and do not necessarily reflect those of the Systematic Reviews Programme, NIHR, NHS or the Department of Health. 


\section{R E F E R E N C E S}

\section{References to studies included in this review}

Brocks 1984 \{published data only\}

Brocks V, Philipsen T, Secher NJ. A randomized trial of external cephalic version with tocolysis in late pregnancy. British Journal of Obstetrics and Gynaecology 1984;91:653-6.

\section{Dafallah 2004 \{published data only\}}

Dafallah SE, Elhag SM. The role of external cephalic version on the presentation at delivery. Saudi Medical Journal 2004;25(3):386-8.

\section{Hindawi 2005 \{published data only\}}

Hindawi I. Value and pregnancy outcome of external cephalic version. Eastern Mediterranean Health Journal 2005;11(4):633-9.

\section{Hofmeyr 1983 \{published data only\}}

Hofmeyr GJ. Effect of external cephalic version in late pregnancy on breech presentation and caesarean section rate: a controlled trial. British Journal of Obstetrics and Gynaecology 1983;90:392-9.

\section{Mahomed 1991 \{published data only\}}

Mahomed K, Seeras R, Coulson R. External cephalic version at term. A randomised controlled trial using tocolysis. British Journal of Obstetrics and Gynaecology 1991;98:8-13.

\section{Rita 2012 \{published data only\}}

Rita, Mehbooba, Sultana S, Khurshid R. A randomized trial of external cephalic version in late pregnancy. JK Science 2012;14(1):25-9.

\section{Van de Pavert 1990 \{published data only\}}

Van de Pavert R, Gravenhorst JB, Keirse MJNC. Value of external version in breech presentation at term. Nederlands Tijdschrift voor Geneeskunde 1990;134:2245-8.

Van Dorsten 1981 \{published data only\}

Van Dorsten JP, Schifrin BS, Wallace RL. Randomized control trial of external cephalic version with tocolysis in late pregnancy. American Journal of Obstetrics and Gynecology 1981;141:417-24.

\section{References to studies excluded from this review}

Besio 1994 \{published data only\}

Besio M, Coto M. Evaluation of the external cephalic version in the management of dystocia (published erratum appears in Revista Chilena de Obstetricia y Ginecologia 1995;60(2):145). Revista Chilena de Obstetricia y Ginecologia 1994;59:422-7.

\section{El-Muzaini 2008a \{published data only\}}

El-Muzaini MF, Felimban HM, Al-Hazmi NM, Shabaan LA, Namankani FY, Fathudein MA. Breech in labor, to turn or not to turn?. BJOG: an international journal of obstetrics and gynaecology 2008;115(s1):77.
El-Muzaini 2008b \{published data only\}

El-Muzaini MF, Felimban HM, Al-Hazmi NM, Shabaan LA, Namankani FY, Fathudein MA. Breech with previous scar, is ECV a good option?. BJOG: an international journal of obstetrics and gynaecology 2008;115(s1):77-8.

\section{Rust 2005 \{published data only\}}

Rust O, Atlas R, Gersbach E, Roberts W, Larkin R, Hess LW. A randomized trial of late versus early external cephalic version for the treatment of abnormal presentation at term [abstract]. American Journal of Obstetrics and Gynecology 2005;193(6 Suppl):S129.

\section{Stine 1985 \{published data only\}}

Stine LE, Phelan JP, Wallace R, Eglinton GS, Van Dorsten JP, Schifrin BS. Update on external cephalic version performed at term. Obstetrics \& Gynecology 1985;65:642-6.

\section{Van Veelen 1989 \{published data only\}}

Van Veelen AJ, Van Cappellen AW, Flu PK, Straub MJPF, Wallenburg HCS. Effect of external cephalic version in late pregnancy on presentation at delivery: a randomized controlled trial. British Journal of Obstetrics and Gynaecology 1989;96:916-21.

\section{Additional references}

\section{Ben-Haroush 2002}

Ben-Haroush A, Perri T, Bar J, Yogev Y, Bar-Hava I, Hod M, et al. Mode of delivery following successful external cephalic version. American Journal of Perinatology 2002;19:355-60.

\section{Boucher 2003}

Boucher M, Bujold E, Marquette GP, Vezina Y. The relationship between amniotic fluid index and successful external cephalic version: a 14-year experience. American Journal of Obstetrics and Gynecology 2003;189:751-4.

\section{Bradley-Watson 1975}

Bradley-Watson PJ. The decreasing value of external cephalic version in modern obstetric practice. American Journal of Obstetrics and Gynecology 1975;123:237-40.

\section{Brosset 1956}

Brosset $A$. The value of prophylactic external version in cases of breech presentation. Acta Obstetricia et Gynecologica Scandinavica 1956;35:555-62.

\section{Chan 2004}

Chan LY, Leung TY, Fok WY, Chan LW, Lau TK. Prediction of successful vaginal delivery in women undergoing external cephalic version at term for breech presentation. European Journal of Obstetrics \& Gynecology and Reproductive Biology 2004;116:39-42. 


\section{Chan 2004b}

Chan LY, Tang JL, Tsoi KF, Fok WY, Chan LW, Lau TK. Intrapartum cesarean delivery after successful external cephalic version: a meta-analysis. Obstetrics \& Gynecology 2004;104:155-60.

\section{Chan 2004c}

Chan LY, Leung TY, Fok WY, Chan LW, Lau TK. Cord blood acidbase status at delivery after successful external cephalic version. Acta Obstetricia et Gynecologica Scandinavica 2004;83:436-9.

\section{Cluver 2012}

Cluver C, Hofmeyr GJ, Gyte GML, Sinclair M. Interventions for helping to turn term breech babies to head first presentation when using external cephalic version. Cochrane Database of Systematic Reviews 2012, Issue 1. [DOI: 10.1002/14651858.CD000184.pub3]

\section{Collaris 2004}

Collaris RJ, Oei SG. External cephalic version: a safe procedure? A systematic review of version-related risks. Acta Obstetricia et Gynecologica Scandinavica 2004;83:511-8.

\section{Cooper 2002}

Cooper GM, Lewis G, Neilson J. Editorial: confidential enquiries into maternal deaths. British Journal of Anaesthesia 2002;89(3):369-72.

\section{Danielian 1996}

Danielian PJ, Wang J, Hall MH. Long term outcome by method of delivery of fetuses in breech presentation at term: population based follow up. BMJ 1996;312:1451-3.

\section{Dashe 2002}

Dashe JS, Mclntire DD, Ramus RM, Santos-Ramos R, Twickler DM. Persistence of placenta previa according to gestational age at ultrasound. Obstetrics \& Gynecology 2002;99(5 Pt 1):692-7.

\section{De Hundt 2014}

de Hundt M, Velzel J, de Groot CJ, Mol BW, Kok M. Mode of delivery after successful external cephalic version: a systematic review and meta-analysis. Obstetrics \& Gynecology 2014;123(6):1327-34.

\section{Devendra 2002}

Devendra K. Introducing routine external cephalic version for the management of the malpresenting fetus near term. Medical Journal of Malaysia 2002;57:454-9.

\section{Elbourne 2002}

Elbourne DR, Altman DG, Higgins JPT, Curtin F, Vaillancourt JM. Meta-analyses involving cross-over trials: methodological issues. International Journal of Epidemiology 2002;31:140-9.

\section{Ferber 1999}

Ferber A, Peleg D, Bar-Hava I, Orvieto R, Ben-Rafael Z. Optimal fetal outcome despite persistent sinusoidal pattern after external cephalic version. Journal of Obstetrics and Gynaecology 1999;19:314-5.

\section{Ferguson 1985}

Ferguson JE, Dyson DC. Intrapartum external cephalic version. American Journal of Obstetrics and Gynecology 1985;152:297-8.

\section{Flamm 1991}

Flamm BL, Fried MW, Lonky NM, Giles WS. External cephalic version after previous cesarean section. American Journal of Obstetrics and Gynecology 1991;165:370-2.

\section{Fortunato 1988}

Fortunato SJ, Mercer LJ, Guzick DS. External cephalic version with tocolysis: factors associated with success. Obstetrics \& Gynecology 1988;72:59-62.

\section{Fung Kee Fung 2003}

Fung Kee Fung K, Eason E, Crane J, Armson A, De La Ronde S, Farine D, et al. Prevention of Rh alloimmunization. Journal of Obstetrics and Gynaecology Canada: JOGC 2003;25:765-73.

\section{Gamble 2000}

Gamble JA, Creedy DK. Women's request for a cesarean section: a critique of the literature. Birth 2000;27(4):256-63.

\section{Geary 1997}

Geary M, Fanagan M, Boylan P. Maternal satisfaction with management of labour and preference for mode of delivery. Journal of Perinatal Medicine 1997;25(5):433-9.

\section{Gilliam 2002}

Gilliam M, Rosenberg D, Davis F. The likelihood of placenta previa with greater number of cesarean deliveries and higher parity. Obstetrics \& Gynecology 2002;99(6):976-80.

\section{Goffinet 2006}

Goffinet F, Carayol M, Foidart JM, Alexander S, Uzan S, Subtil D, Bréart G, PREMODA Study Group. Is planned vaginal delivery for breech presentation at term still an option? Results of an observational prospective survey in France and Belgium. American Journal of Obstetrics and Gynecology 2006;194(4):1002-11.

\section{Grade 2008 [Computer program]}

Version 3.6 for Windows. GRADEpro [Computer program]. Jan Brozek, Andrew Oxman, Holger Schünemann. Version 3.6 for Windows, 2008.

\section{Guyer 2001}

Guyer $\mathrm{CH}$, Heard MJ. A prospective audit of external cephalic version at term: are ultrasound parameters predictive of outcome?. Journal of Obstetrics and Gynaecology 2001;21:580-2.

\section{Hall 1999}

Hall MH, Bewley S. Maternal mortality and mode of delivery. Lancet 1999;354(1180):776.

\section{Higgins 2011}

Higgins JPT, Green S, editors. Cochrane Handbook for Systematic Reviews of Interventions Version 5.1.0 [updated March 2011]. The Cochrane Collaboration, 2011. Available from www.cochrane-handbook.org. 


\section{Hildingsson 2002}

Hildingsson I, Radestad I, Rubertsson C. Waldenstrom U. Few women wish to be delivered by caesarean section. BJOG: an international journal of obstetrics and gynaecology 2002;109(6):618-23.

\section{Hofmeyr 1986}

Hofmeyr GJ, Sadan O, Myer IG, Gallal KC, Simko G. External cephalic version and spontaneous version rates: ethnic and other determinants. British Journal of Obstetrics and Gynaecology 1986;93:13-6.

\section{Hofmeyr 1989}

Hofmeyr GJ. Breech presentation and abnormal lie in late pregnancy. In: Chalmers I, Enkin MW, Keirse MJNC editor(s). Effective Care in Pregnancy and Childbirth. Oxford: Oxford University Press, 1989:653-65.

\section{Hofmeyr 1991}

Hofmeyr GJ. External cephalic version at term: how high are the stakes?. British Journal of Obstetrics and Gynaecology 1991;98:1-3.

\section{Hofmeyr 1992}

Hofmeyr GJ. Breech presentation and shoulder dystocia in childbirth. Current Opinion in Obstetrics and Gynecology 1992;4:807-12.

\section{Hofmeyr 1993}

Hofmeyr GJ. External cephalic version at term. Fetal Maternal Medicine Review 1993;5:213-22.

\section{Hofmeyr 2000}

Hofmeyr GJ, Kulier R. Cephalic version by postural management for breech presentation. Cochrane Database of Systematic Reviews 2000, Issue 3. [DOI: 10.1002/14651858.CD000051]

\section{Hofmeyr 2003}

Hofmeyr GJ, Hannah M, Lawrie TA. Planned caesarean section for term breech delivery. Cochrane Database of Systematic Reviews 2003, Issue 2. [DOI: 10.1002/14651858.CD000166]

\section{Hofmeyr 2004}

Hofmeyr GJ. Obstructed labor: using better technologies to reduce mortality. International Journal of Gynaecology \& Obstetrics 2004;85 Suppl 1:S62-72.

\section{Hofmeyr 2005}

Hofmeyr GJ, Hannah M, Lawrie TA. Planned caesarean section for term breech delivery. Cochrane Database of Systematic Reviews 2003, Issue 2. [DOI: 10.1002/14651858.CD000166]

\section{Holmes 2004}

Holmes W, Hofmeyr GJ. Management of breech presentation in areas with high prevalence of HIV infection. International Journal of Gynaecology \& Obstetrics 2004;87:272-6.

\section{Hughes 1997}

Hughes GW. Establishing an external cephalic version clinic: outcome of the first year. Journal of Obstetrics and Gynaecology 1997;17:127-31.

\section{Hutton 2006}

Hutton EK, Hofmeyr GJ. External cephalic version for breech presentation before term. Cochrane Database of Systematic Reviews 2006, Issue 1. [DOI: 10.1002/14651858.CD000084.pub2]

\section{Impey 1999}

Impey L, Lissoni D. Outcome of external cephalic version after 36 weeks' gestation without tocolysis. Journal of Maternal-Fetal Medicine 1999;8(5):203-7.

\section{Impey 2005}

Impey L, Pandit M. Tocolysis for repeat external cephalic version in breech presentation at term: a randomised, double-blinded, placebo-controlled trial. BJOG: an international journal of obstetrics and gynaecology 2005;112(5):627-31.

\section{LaSala 1987}

LaSala AP, Berkeley AS. Primary cesarean section and subsequent fertility. American Journal of Obstetrics and Gynecology 1987;157(2):379-83.

\section{Lau 1997}

Lau TK, Lo KWK, Wan D, Rogers MS. Predictors of successful external cephalic version at term: a prospective study. British Journal of Obstetrics and Gynaecology 1997;104:798-802.

\section{Le Bret 2004}

Le Bret T, Grange G, Goffinet F, Cabrol D. External cephalic version: experience about 237 versions at Port-Royal maternity. Journal de Gynecologie, Obstetrique et Biologie de la Reproduction (Paris) 2004;33:297-303.

\section{Lojacono 2003}

Lojacono A, Donarini G, Valcamonico A, Soregaroli M, Frusca T. External cephalic version for breech presentation at term: an effective procedure to reduce the caesarean section rate. Minerva Ginecologica 2003;55:519-24.

\section{Lydon-Rochelle 2001}

Lydon-Rochelle M, Holt VL, Easterling TR, Martin DP. First-birth cesarean and placental abruption or previa at second birth. Obstetrics \& Gynecology 2001;97(5 Pt 1):765-9.

\section{Minkoff 2003}

Minkoff $\mathrm{H}$, Chervenak FA. Elective primary cesarean delivery. New England Journal of Medicine 2003;384(10):946-50.

\section{Murray-Davis 2012}

Murray-Davis B, Marion A, Malott A, Reitsma A, Hutton RM and the Early ECV2 Trial Collaborative Group. Women's experiences of participating in the early external cephalic version 2 trial. Birth 2012;39(1):30-8.

\section{Nassar 2007}

Nassar N, Roberts CL, Raynes-Greenow CH, Barratt A, Peat B, on behalf of the Decision Aid for Breech Presentation Trial Collaborators. Evaluation of a decision aid for women with breech presentation at term: a randomised controlled trial. British Journal of Obstetrics and Gynaecology 2007;114:325-33. 


\section{Nzewi 1999}

Nzewi N, Clerk P, Bowen-Simpkins C. Prolonged fetal tachycardia-an unusual complication of external cephalic version. Journal of Obstetrics and Gynaecology 1999;19:427-8.

\section{Owens 2003}

Owens M, Bhullar A, Carlan SJ, O'Brien WF, Hirano K. Effect of fundal pressure on maternal to fetal microtransfusion at the time of cesarean delivery. Journal of Obstetrics and Gynaecology Research 2003;29:152-6.

\section{Papp 2004}

Papp S, Dhaliwal G, Davies G, Borschneck D. Fetal femur fracture and external cephalic version. Obstetrics \& Gynecology 2004;104:1154-6.

\section{Raynes-Greenow 2004}

Raynes-Greenow CH, Roberts CL, Barratt A, Brodrick B, Peat B. Pregnant women's preferences and knowledge of term breech management, in an Australian setting. Midwifery 2004;20:181-7.

\section{RevMan 2014 [Computer program]}

The Nordic Cochrane Centre, The Cochrane Collaboration. Review Manager (RevMan). Version 5.3. Copenhagen: The Nordic Cochrane Centre, The Cochrane Collaboration, 2014.

\section{Schachter 1994}

Schachter M, Kogan S, Blickstein I. External cephalic version after previous cesarean section - a clinical dilemma. International Journal of Gynecology \& Obstetrics 1994;45:17-20.

\section{Schunemann 2009}

Schunemann HJ. GRADE: from grading the evidence to developing recommendations. A description of the system and a proposal regarding the transferability of the results of clinical research to clinical practice [GRADE: Von der Evidenz zur Empfehlung. Beschreibung des Systems und Losungsbeitrag zur Ubertragbarkeit von Studienergebnissen]. Zeitschrift fur Evidenz, Fortbildung und Qualitat im Gesundheitswesen 2009;103(6):391-400. [PUBMED: 19839216]

\section{Shankar 2004}

Shankar M, Gough GW, Chakravarti S, Vellacott ID. Massive fetomaternal haemorrhage with good perinatal outcome following failed external cephalic version. Fetal Diagnosis and Therapy 2004;19:68-71.

\section{Skupski 2003}

Skupski DW, Harrison-Restelli C, Dupont RB. External cephalic version: an approach with few complications. Gynecologic and Obstetric Investigation 2003;56:83-8.

\section{Tong 2012}

Tong Leung VK, Suen SS, Singh Sahota D, Lau TK, Yeung Leung T. External cephalic version does not increase the risk of intra-uterine death: a 17-year experience and literature review. Journal of Maternal-Fetal \& Neonatal Medicine 2012;25(9):1774-8.

\section{Turnbull 1999}

Turnbull DA, Wilkinson C, Yaser A, Carty V, Svigos JM, Robinson JS. Women's role and satisfaction in the decision to have a caesarean section. Medical Journal of Australia 1999;170(12):580-3.

\section{Vezina 2004}

Vezina Y, Bujold E, Varin J, Marquette GP, Boucher M. Cesarean delivery after successful external cephalic version of breech presentation at term: a comparative study. American Journal of Obstetrics and Gynecology 2004;190:763-8.

\section{Walker 2002}

Walker R, Turnbull D, Wilkinson C. Strategies to address global cesarean section rates: a review of the evidence. Birth 2002;29(1):28-39.

\section{Williams 1999}

Williams J, Bjornsson S, Cameron AD, Mathers A, Yahya SZS, Pell JP. Prospective study of external cephalic version in Glasgow: patient selection, outcome and factors associated with outcome. Journal of Obstetrics and Gynaecology 1999;19:598-601.

\section{Yogev 2002}

Yogev Y, Horowitz E, Ben-Haroush A, Chen R, Kaplan B. Changing attitudes toward mode of delivery and external cephalic version in breech presentations. International Journal of Gynecology \& Obstetrics 2002;79:221-4.

\section{Zhang 1993}

Zhang J, Bowes WA, Fortney JA. Efficacy of external cephalic version: a review. Obstetrics \& Gynecology 1993;82:306-12.

\section{References to other published versions of this review} Hofmeyr 1995

Hofmeyr GJ. External cephalic version at term. [revised 04 October 1993]. In: Enkin MW, Keirse MJNC, Renfrew MJ, Neilson JP, Crowther C (eds.) Pregnancy and Childbirth Module. In: The Cochrane Pregnancy and Childbirth Database [database on disk and CDROM]. The Cochrane Collaboration; Issue 2, Oxford: Update Software; 1995.

\section{Hofmeyr 1996}

Hofmeyr GJ, Kulier R. External cephalic version for breech presentation at term. Cochrane Database of Systematic Reviews 1996, Issue 1. [DOI: 10.1002/14651858.CD000083]

\section{Hofmeyr 2012}

Hofmeyr GJ, Kulier R. External cephalic version for breech presentation at term. Cochrane Database of Systematic Reviews 2012, Issue 10. [DOI: 10.1002/14651858.CD000083.pub2] 
CHARACTERISTICS OF STUDIES

Characteristics of included studies [ordered by study ID]

Brocks 1984

Methods 65 women who agreed to enter the trial were "randomly allocated" to ECV or control group. A further 65 women who had ECV or no ECV according to request are not included in this review as they were not randomised.

\begin{tabular}{ll}
\hline Participants & $\begin{array}{l}\text { Inclusion criteria: singleton breech presentation on ultrasound in 37th week. Agree to enter study. Ex- } \\
\text { clusion criteria: contraindication to ECV. }\end{array}$ \\
\hline Interventions & $\begin{array}{l}\text { Single ECV attempt following ritodrine } 15 \mu \mathrm{g} / \text { minute for } 15 \text { minutes (31 women). ECV repeated success- } \\
\text { fully in } 2 \text { women in whom reversion to breech occurred. Compared with no ECV attempt (34 women). }\end{array}$ \\
\hline Outcomes & Presentation at delivery; method of delivery. \\
\hline Notes & $\begin{array}{l}\text { Neonatal outcomes given according to presentation rather than allocation and therefore not included } \\
\text { in the review. Location: outpatient clinic, Denmark. }\end{array}$
\end{tabular}

\section{Risk of bias}

\begin{tabular}{lll}
\hline Bias & Authors' judgement & Support for judgement \\
\hline $\begin{array}{l}\text { Random sequence genera- } \\
\text { tion (selection bias) }\end{array}$ & Unclear risk & "Randomly allocated." \\
\hline $\begin{array}{l}\text { Allocation concealment } \\
\text { (selection bias) }\end{array}$ & Unclear risk & Not described. \\
\hline $\begin{array}{l}\text { Blinding of participants } \\
\text { and personnel (perfor- } \\
\text { mance bias) }\end{array}$ & High risk & $\begin{array}{l}\text { Women were selected for the study if they had specified that they wanted a } \\
\text { vaginal birth. Women would have been aware of the intervention and this may } \\
\text { have affected decisions regarding care in later pregnancy and at the birth. } \\
\text { Staff would be aware of intervention and this may have affected other aspects } \\
\text { of care and decision-making at the birth. This may have had an impact on out- } \\
\text { comes such as CS. }\end{array}$
\end{tabular}

Blinding of outcome as- Unclear risk sessment (detection bias) All outcomes
It was not clear whether outcome assessment was carried out by staff who were involved in care. It is unlikely that lack of blinding of outcome assessors could have influenced some of the outcomes measured, but assessment of the infant may have been affected by knowledge of randomisation group.

\begin{tabular}{lll}
\hline $\begin{array}{l}\text { Incomplete outcome data } \\
\text { (attrition bias) } \\
\text { All outcomes }\end{array}$ & Unclear risk & $\begin{array}{l}\text { Neonatal outcomes given according to presentation not allocation, and in- } \\
\text { clude non-randomised participants. They are therefore not included in the re- } \\
\text { view. }\end{array}$ \\
\hline $\begin{array}{l}\text { Selective reporting (re- } \\
\text { porting bias) }\end{array}$ & Unclear risk & $\begin{array}{l}\text { Neonatal outcomes given according to presentation not allocation. Unclear } \\
\text { whether all prespecified outcomes were reported. }\end{array}$ \\
\hline Other bias & Unclear risk & $\begin{array}{l}\text { Neonatal outcomes given according to presentation rather than allocation and } \\
\text { therefore not included in the review. No information on whether the interven- } \\
\text { tion and control groups were comparable. }\end{array}$ \\
\hline
\end{tabular}


Dafallah 2004

\section{Methods}

Women were "randomly allocated" to the study group or the control group. Randomisation was stratified by parity (nulliparas and multiparas).

\section{Participants}

620 healthy women with uncomplicated breech pregnancy at 36-38 weeks in Sudan from 1995-2001 (135 nulliparas and 175 multiparas in the study group compared to 125 nulliparas and 185 multiparas in the control group). Ultrasound examination before randomisation excluded congenital malformation, oligohydramnios, placenta praevia, uterine abnormality. Other exclusions were previous CS, APH, hypertensive disorders, IUGR.

\begin{tabular}{ll}
\hline Interventions & $\begin{array}{l}\text { ECV attempt of up to } 5 \text { minutes without tocolysis versus no ECV attempt. If the procedure failed or } \\
\text { when reversion occurred, the manoeuvre was repeated up to } 3 \text { times at subsequent antenatal visits. }\end{array}$ \\
\hline Outcomes & Mode of delivery, Apgar scores at $1,5,10$ min, fetal weight. \\
\hline Notes & $\begin{array}{l}\text { Baseline characteristics were similar except for maternal age (multiparas in control group older than } \\
\text { study group). There were } 750 \mathrm{ECV} \text { attempts in } 310 \text { women: } 196 / 750 \text { successful }(26 \%) \text { with greater suc- } \\
\text { cess in multiparas. Apgar scores not reported. Additional information requested but not obtained from } \\
\text { authors. Location: antenatal care clinic at Wad Medani Teaching Hospital, Sudan. }\end{array}$
\end{tabular}

\section{Risk of bias}

\begin{tabular}{|c|c|c|}
\hline Bias & Authors' judgement & Support for judgement \\
\hline $\begin{array}{l}\text { Random sequence genera- } \\
\text { tion (selection bias) }\end{array}$ & Unclear risk & 'Randomly allocated.' \\
\hline $\begin{array}{l}\text { Allocation concealment } \\
\text { (selection bias) }\end{array}$ & Unclear risk & Not described. \\
\hline $\begin{array}{l}\text { Blinding of participants } \\
\text { and personnel (perfor- } \\
\text { mance bias) } \\
\text { All outcomes }\end{array}$ & High risk & $\begin{array}{l}\text { Women would have been aware of the intervention and this may have affect- } \\
\text { ed decisions re care in later pregnancy and at the birth. It was stated that ECV } \\
\text { was carried out by a single obstetrician. It is not clear if this same obstetrician } \\
\text { cared for women in the control group or was involved in other aspects of care. } \\
\text { Staff would be aware of intervention and this may have affected other aspects } \\
\text { of care and decision-making at the birth. This may have had an impact on out- } \\
\text { comes such as CS. }\end{array}$ \\
\hline
\end{tabular}

\begin{tabular}{|c|c|c|}
\hline $\begin{array}{l}\text { Blinding of outcome as- } \\
\text { sessment (detection bias) } \\
\text { All outcomes }\end{array}$ & Unclear risk & $\begin{array}{l}\text { It was not clear whether outcome assessment was carried out by staff who } \\
\text { were involved in care. It is unlikely that lack of blinding of outcome assessors } \\
\text { would have influenced some of the outcomes measured. }\end{array}$ \\
\hline
\end{tabular}

\begin{tabular}{lll}
\hline $\begin{array}{l}\text { Incomplete outcome data } \\
\text { (attrition bias) } \\
\text { All outcomes }\end{array}$ & Low risk & No loss to follow-up reported. \\
\hline $\begin{array}{l}\text { Selective reporting (re- } \\
\text { porting bias) }\end{array}$ & High risk & $\begin{array}{l}\text { The authors do not report on all prespecified outcomes, e.g. Apgar scores, or } \\
\text { other key outcomes of interest, e.g. morbidity. }\end{array}$ \\
\hline Other bias & High risk & Potentially high risk of bias. \\
\hline
\end{tabular}

Hindawi 2005

\begin{tabular}{ll}
\hline Methods & Stated 'randomised controlled trial'. No details of randomisation or allocation concealment are given. \\
\hline Participants & $\begin{array}{l}192 \text { singleton breech pregnancies }>37 \text { weeks' gestation at King Hussein Medical Center in Amman, Jor- } \\
\text { dan (Jan 1999-Dec 2001). Included if: reactive CTG and fetal movements, known Rhesus group, fasted }\end{array}$ \\
\hline
\end{tabular}


Hindawi 2005 (Continued)

for 6 hours prior to procedure. Excluded if: fetal abnormality, abnormal CTG, placenta praevia, established labour, ruptured membranes, gestational diabetes requiring insulin, IUGR, proteinuric hypertension disorders, previous CS, oligohydramnios, polyhydramnios.

\begin{tabular}{|c|c|}
\hline Interventions & ECV (90) with tocolysis vs no ECV (102). \\
\hline Outcomes & 'All clinical details concerning the pregnancy, ECV and delivery were recorded and reviewed.' \\
\hline Notes & $\begin{array}{l}\text { No explanation given for the large difference in group size ( } 90 \text { vs 102). Baseline characteristics similar } \\
\text { except for fetal weight ( } 3350 \text { in ECV group vs } 3120 \text { in control group). Outcomes not clearly prespecified. } \\
\text { High risk of bias. Additional information requested but not obtained from author. Location: outpatient } \\
\text { clinic, King Hussein Medical Centre, Jordan. }\end{array}$ \\
\hline
\end{tabular}

\section{Risk of bias}

\begin{tabular}{|c|c|c|}
\hline Bias & Authors' judgement & Support for judgement \\
\hline $\begin{array}{l}\text { Random sequence genera- } \\
\text { tion (selection bias) }\end{array}$ & Unclear risk & Stated 'randomised'. No other details provided. \\
\hline $\begin{array}{l}\text { Allocation concealment } \\
\text { (selection bias) }\end{array}$ & Unclear risk & Not described. \\
\hline $\begin{array}{l}\text { Blinding of participants } \\
\text { and personnel (perfor- } \\
\text { mance bias) } \\
\text { All outcomes }\end{array}$ & High risk & $\begin{array}{l}\text { Women would have been aware of the intervention and this may have affect- } \\
\text { ed decisions re care in later pregnancy and at the birth. Staff would be aware } \\
\text { of intervention and this may have affected other aspects of care and deci- } \\
\text { sion-making at the birth. This may have had an impact on outcomes such as } \\
\text { CS/elective CS. }\end{array}$ \\
\hline $\begin{array}{l}\text { Blinding of outcome as- } \\
\text { sessment (detection bias) } \\
\text { All outcomes }\end{array}$ & Unclear risk & $\begin{array}{l}\text { It was not clear whether outcome assessment was carried out by staff who } \\
\text { were involved in care. It is unlikely that lack of blinding of outcome assessors } \\
\text { would have influenced some of the outcomes measured. }\end{array}$ \\
\hline $\begin{array}{l}\text { Incomplete outcome data } \\
\text { (attrition bias) } \\
\text { All outcomes }\end{array}$ & Unclear risk & $\begin{array}{l}\text { Unclear whether there were protocol deviations, post randomisation exclu- } \\
\text { sions or missing data. }\end{array}$ \\
\hline $\begin{array}{l}\text { Selective reporting (re- } \\
\text { porting bias) }\end{array}$ & High risk & Outcomes are not clearly prespecified. \\
\hline Other bias & High risk & $\begin{array}{l}\text { Baseline difference in fetal weight; large unexplained difference in group size } \\
\text { (control group } 13 \% \text { bigger than treatment group). Potentially high risk of bias. }\end{array}$ \\
\hline
\end{tabular}

Hofmeyr 1983

$\begin{array}{ll}\text { Methods } & \text { 2-arm randomised trial. Women were allocated to the intervention or control group by randomly or- } \\ \text { dered, concealed cards. }\end{array}$
Participants Inclusion criteria: singleton breech presentation on ultrasound examination at 36 or more weeks' ges- tation; consent to participate.
Exclusion criteria: contraindication to ECV.
Interventions
ECV attempt initially without tocolysis (30 women). If unsuccessful ( 7 cases), attempt repeated follow- ing hexoprenaline $10 \mu \mathrm{g}$ by slow IVI injection. Compared with no ECV attempt (30 women).


Hofmeyr 1983 (Continued)

Notes
Location: Baragwanath Hospital, South Africa (admitted from hospital antenatal clinic \& district clinics in Soweto).

\section{Risk of bias}

\begin{tabular}{|c|c|c|}
\hline Bias & Authors' judgement & Support for judgement \\
\hline $\begin{array}{l}\text { Random sequence genera- } \\
\text { tion (selection bias) }\end{array}$ & Low risk & Previously shuffled cards marked 'V' or ' $C$ '. \\
\hline $\begin{array}{l}\text { Allocation concealment } \\
\text { (selection bias) }\end{array}$ & Low risk & Concealed cards. \\
\hline $\begin{array}{l}\text { Blinding of participants } \\
\text { and personnel (perfor- } \\
\text { mance bias) } \\
\text { All outcomes }\end{array}$ & Unclear risk & $\begin{array}{l}\text { Women would have been aware of allocation and may have discussed it with } \\
\text { staff providing care. It was stated that the staff carrying out the ECV were not } \\
\text { involved in the subsequent care of women. }\end{array}$ \\
\hline $\begin{array}{l}\text { Blinding of outcome as- } \\
\text { sessment (detection bias) } \\
\text { All outcomes }\end{array}$ & Low risk & $\begin{array}{l}\text { Assessment was from records (it was not clear whether attempted ECV or ran- } \\
\text { domisation group was stated in the records). It is unlikely that those collecting } \\
\text { information could have influenced maternal and infant outcomes reported. }\end{array}$ \\
\hline $\begin{array}{l}\text { Incomplete outcome data } \\
\text { (attrition bias) } \\
\text { All outcomes }\end{array}$ & Low risk & No loss to follow-up reported. \\
\hline $\begin{array}{l}\text { Selective reporting (re- } \\
\text { porting bias) }\end{array}$ & Low risk & All prespecified outcomes reported. \\
\hline Other bias & Low risk & \\
\hline
\end{tabular}

\section{Mahomed 1991}

\begin{tabular}{ll}
\hline Methods & $\begin{array}{l}\text { 2-arm randomised trial. Allocation by consecutively numbered sealed opaque envelopes, randomised } \\
\text { in blocks of } 6 .\end{array}$ \\
\hline Participants & $\begin{array}{l}\text { Inclusion criteria: singleton breech presentation at } 37 \text { weeks or more; consent to participate. Exclusion } \\
\text { criteria: contraindication to ECV; non-reactive nonstress test. }\end{array}$ \\
\hline Interventions & $\begin{array}{l}\text { ECV attempt following hexoprenaline } 10 \mu \mathrm{g} \text { intravenously over } 1 \text { minute (103 women), compared with } \\
\text { no ECV attempt (105 women). }\end{array}$ \\
\hline Outcomes & $\begin{array}{l}\text { Presentation at delivery; CS rate; } 5 \text { minute Apgar score }<7 \text { and < 5; perinatal mortality; enrol- } \\
\text { ment-labour interval; gestation at delivery. }\end{array}$ \\
\hline Notes & $\begin{array}{l}\text { Factors affecting ECV success rate evaluated in the } 103 \text { women in the trial together with another } 104 \\
\text { non-trial ECV attempts. In the latter group } 1 \text { stillbirth occurred } 17 \text { days after successful ECV. The baby } \\
\text { was born with the cord tightly around the neck. In the randomised to ECV group, a baby born vaginal- } \\
\text { ly } 23 \text { days after successful version was severely asphyxiated and died at } 3 \text { days old. } 2 \text { perinatal deaths } \\
\text { occurred in the control group following vaginal breech delivery. Location: Harare maternity hospital, } \\
\text { Harare, Zimbabwe. }\end{array}$ \\
\hline
\end{tabular}

\section{Risk of bias}

\section{Authors' judgement Support for judgement}


Mahomed 1991 (Continued)

\begin{tabular}{lll}
$\begin{array}{l}\text { Random sequence genera- } \\
\text { tion (selection bias) }\end{array}$ & Low risk & Randomised in blocks of 6. \\
\hline $\begin{array}{l}\text { Allocation concealment } \\
\text { (selection bias) }\end{array}$ & Low risk & Sealed opaque envelopes. \\
\hline
\end{tabular}

Blinding of participants High risk

and personnel (perfor-

Women would have been aware of the intervention and this may have affect-

mance bias)

All outcomes ed decisions re care in later pregnancy and at the birth. Staff would be aware of intervention and this may have affected other aspects of care and decision-making at the birth. This may have had an impact on outcomes such as CS/elective CS.

\begin{tabular}{lll}
\hline $\begin{array}{l}\text { Blinding of outcome as- } \\
\text { sessment (detection bias) } \\
\text { All outcomes }\end{array}$ & Low risk & $\begin{array}{l}\text { Assessment was from records It was stated that those collecting data on con- } \\
\text { dition of the newborn were blind to allocation. It is unlikely that those collect- } \\
\text { ing information could have influenced other outcomes reported. }\end{array}$ \\
\hline $\begin{array}{l}\text { Incomplete outcome data } \\
\text { (attrition bias) } \\
\text { All outcomes }\end{array}$ & Low risk & No withdrawals or loss to follow-up. \\
\hline $\begin{array}{l}\text { Selective reporting (re- } \\
\text { porting bias) }\end{array}$ & Unclear risk & $\begin{array}{l}\text { Assessed from published report, unclear whether all prespecified outcomes } \\
\text { were reported. }\end{array}$ \\
\hline Other bias & Unclear risk & $\begin{array}{l}\text { The ECV group contained higher numbers of women with fundal placentas, the } \\
\text { clinical implications of this are unclear. }\end{array}$ \\
\hline
\end{tabular}

Rita 2012

$\begin{array}{ll}\text { Methods } & \text { 2-arm randomised trial of ECV after } 37 \text { weeks' gestation. } 60 \text { women were recruited after a routine ul- } \\ \text { trasound at } 37 \text { weeks had shown breech presentation, and were randomised using consecutively num- } \\ \text { bered opaque envelopes. Women were seen weekly for routine antenatal care. }\end{array}$

Participants Inclusion criteria: $\geq 37$ weeks' GA (ultrasound confirmed), singleton, breech presentation.

Exclusion criteria: APH, placenta praevia, uterine anomalies, severe proteinuric hypertension, diabetes, cardiac disease, conditions favouring premature labour, rhesus negative mother, ruptured membranes, previous 2 or more CSs.

\begin{tabular}{ll}
\hline Interventions & ECV (single attempt, over a maximum of 5 minutes) (30 women), compared with no ECV attempt (30 \\
women).
\end{tabular}

Cephalic presentation during labour, fetal heart rate abnormality during and after procedure, mode of
delivery, perinatal mortality and morbidity (Apgar score, NICU admission).

Notes Location: India.

\section{Risk of bias}

\begin{tabular}{lll}
\hline Bias & Authors' judgement & Support for judgement \\
\hline $\begin{array}{l}\text { Random sequence genera- } \\
\text { tion (selection bias) }\end{array}$ & Unclear risk & Stated 'randomised'. No other details provided. \\
\hline $\begin{array}{l}\text { Allocation concealment } \\
\text { (selection bias) }\end{array}$ & Low risk & Consecutively numbered sealed opaque envelopes. \\
\hline
\end{tabular}


Rita 2012 (Continued)

Blinding of participants High risk No blinding. Women would have been aware of the intervention and this may and personnel (perforhave affected decisions re care in later pregnancy and at the birth. Staff would mance bias)

All outcomes be aware of intervention and this may have affected other aspects of care and decision-making at the birth. This may have had an impact on outcomes such as CS/elective CS.

\begin{tabular}{lll}
$\begin{array}{l}\text { Blinding of outcome as- } \\
\text { sessment (detection bias) }\end{array}$ & Unclear risk & $\begin{array}{l}\text { No blinding described. Not clear if the same staff assessed outcomes and were } \\
\text { involved in care. It is possible that lack of blinding could affect assessment of } \\
\text { All outcomes }\end{array}$ \\
\hline
\end{tabular}

\begin{tabular}{lll}
\hline $\begin{array}{l}\text { Incomplete outcome data } \\
\text { (attrition bias) } \\
\text { All outcomes }\end{array}$ & Low risk & All women appear to be included in the analysis. \\
\hline $\begin{array}{l}\text { Selective reporting (re- } \\
\text { porting bias) }\end{array}$ & Unclear risk & $\begin{array}{l}\text { Assessed from published report, unclear whether all prespecified outcomes } \\
\text { were reported. }\end{array}$ \\
\hline Other bias & Unclear risk & $\begin{array}{l}\text { The ECV group contained higher numbers of women with fundal placentas, the } \\
\text { clinical implications of this are unclear. }\end{array}$ \\
\hline
\end{tabular}

\section{Van de Pavert 1990}

\begin{tabular}{ll}
\hline Methods & $\begin{array}{l}\text { 2-arm randomised trial. Randomisation by sealed envelope. Analysis was according to intention-to- } \\
\text { treat. }\end{array}$ \\
\hline Participants & $\begin{array}{l}\text { Inclusion criteria: singleton breech presentation at more than } 36 \text { weeks' gestation; agree to participate. } \\
\text { Exclusion criteria: contraindication to ECV. }\end{array}$ \\
\hline Interventions & ECV without tocolysis (25 women), followed by ECV attempt with ritodrine infusion, compared with no \\
& ECV attempt (27 women). \\
\hline Outcomes & Presentation at delivery; CS rate. \\
\hline Notes & $\begin{array}{l}4 \text { in the ECV group refused ECV attempt, while } 5 \text { in the control group had ECV attempt on request. } \\
\text { Analysis was according to intention-to-treat. Location: The Netherlands. }\end{array}$ \\
\hline
\end{tabular}

\section{Risk of bias}

\begin{tabular}{|c|c|c|}
\hline Bias & Authors' judgement & Support for judgement \\
\hline $\begin{array}{l}\text { Random sequence genera- } \\
\text { tion (selection bias) }\end{array}$ & Unclear risk & Stated 'randomised'. No other details provided. \\
\hline $\begin{array}{l}\text { Allocation concealment } \\
\text { (selection bias) }\end{array}$ & Low risk & Sealed envelope. \\
\hline $\begin{array}{l}\text { Blinding of participants } \\
\text { and personnel (perfor- } \\
\text { mance bias) } \\
\text { All outcomes }\end{array}$ & High risk & $\begin{array}{l}\text { Women would have been aware of the intervention and this may have affect- } \\
\text { ed decisions regarding care in later pregnancy and at the birth. Staff would be } \\
\text { aware of intervention and this may have affected other aspects of care and de- } \\
\text { cision-making at the birth. This may have had an impact on outcomes such as } \\
\text { CS/elective CS. } \\
\text { (In this study it was much more likely that women would have a CS if ECV had } \\
\text { been attempted and failed than in women where ECV had never been attempt- } \\
\text { ed, so it is possible than attempt and failure of ECV affects decision-making re- } \\
\text { garding CS.) }\end{array}$ \\
\hline
\end{tabular}


Van de Pavert 1990 (Continued)
Blinding of outcome as- Unclear risk
Not clear if the same staff assessed outcomes and were involved in care. It is sessment (detection bias) possible that lack of blinding could affect assessment of fetal and neonatal All outcomes outcomes.
Incomplete outcome data Unclear risk 4 in the ECV group refused ECV attempt, while 5 in the control group had ECV (attrition bias) attempt on request. Analysis was according to intention-to-treat. Outcomes All outcomes reported for all participants.

\begin{tabular}{lll}
\hline $\begin{array}{l}\text { Selective reporting (re- } \\
\text { porting bias) }\end{array}$ & Unclear risk & $\begin{array}{l}\text { Assessed from published report, unclear whether all prespecified outcomes } \\
\text { were reported. }\end{array}$ \\
\hline Other bias & Unclear risk & $\begin{array}{l}4 \text { in the ECV group refused ECV attempt, while } 5 \text { in the control group had ECV } \\
\text { attempt on request. Analysis was according to intention-to-treat. }\end{array}$ \\
\hline
\end{tabular}

\section{Van Dorsten 1981}

\begin{tabular}{|c|c|}
\hline Methods & 2-arm randomised trial. Allocation by random number table. \\
\hline Participants & $\begin{array}{l}\text { Inclusion criteria: low-risk pregnant women; breech presentation at } 37 \text { to } 39 \text { weeks' gestation; normal } \\
\text { ultrasound examination; reactive nonstress test. Exclusion criteria: medical conditions; hypertension; } \\
\text { premature labour; premature rupture of membranes; suspected impaired fetal growth; previous uter- } \\
\text { ine surgery; multiple gestation; third trimester bleeding. }\end{array}$ \\
\hline Interventions & $\begin{array}{l}\text { ECV attempt following terbutaline sulphate infusion at } 5 \mu \mathrm{g} \text { per minute for } 10 \text { to } 15 \text { minutes ( } 25 \\
\text { women), compared with no ECV attempt ( } 23 \text { women). }\end{array}$ \\
\hline Outcomes & $\begin{array}{l}\text { Presentation at delivery; CS rate; Apgar score }<7 \text { at } 1 \text { and } 5 \text { minutes; enrolment-delivery interval; birth- } \\
\text { weight; meconium during labour or at delivery. }\end{array}$ \\
\hline Notes & $\begin{array}{l}\text { There were } 3 \text { exclusions after selection because of oligohydramnios, placenta praevia and non-reactive } \\
\text { nonstress test. Location: outpatient clinic at Los Angeles County/University of Southern Calfornia Med- } \\
\text { ical Center, USA. }\end{array}$ \\
\hline
\end{tabular}

\section{Risk of bias}

\begin{tabular}{lll}
\hline Bias & Authors' judgement & Support for judgement \\
\hline $\begin{array}{l}\text { Random sequence genera- } \\
\text { tion (selection bias) }\end{array}$ & Low risk & Random number table. \\
\hline $\begin{array}{l}\text { Allocation concealment } \\
\text { (selection bias) }\end{array}$ & Unclear risk & Not described. \\
\hline $\begin{array}{l}\text { Blinding of participants } \\
\text { and personnel (perfor- } \\
\text { mance bias) } \\
\text { All outcomes }\end{array}$ & High risk & $\begin{array}{l}\text { Women would have been aware of the intervention and this may have affect- } \\
\text { ed decisions regarding care in later pregnancy and at the birth. Staff would be } \\
\text { aware of intervention and this may have affected other aspects of care and de- } \\
\text { cision-making at the birth. This may have had an impact on outcomes such as } \\
\text { CS/elective CS. }\end{array}$
\end{tabular}

\begin{tabular}{|c|c|c|}
\hline $\begin{array}{l}\text { Blinding of outcome as- } \\
\text { sessment (detection bias) } \\
\text { All outcomes }\end{array}$ & Unclear risk & $\begin{array}{l}\text { Not clear if the same staff assessed outcomes and were involved in care. It is } \\
\text { possible that lack of blinding could affect assessment of fetal and neonatal } \\
\text { outcomes. }\end{array}$ \\
\hline
\end{tabular}

Incomplete outcome data Low risk 3 post-randomisation exclusions. All women accounted for.

(attrition bias) 
Van Dorsten 1981 (Continued)

All outcomes

\begin{tabular}{|c|c|c|}
\hline $\begin{array}{l}\text { Selective reporting (re- } \\
\text { porting bias) }\end{array}$ & Unclear risk & $\begin{array}{l}\text { Assessed from published report, unclear whether all prespecified outcomes } \\
\text { were reported. }\end{array}$ \\
\hline
\end{tabular}

Other bias Unclear risk 3 post-randomisation exclusions.

APH: antepartum haemorrhage

CS: caesarean section

CTG: cardiotocograph

ECV: external cephalic version

GA: gestational age

IUGR: intrauterine growth restriction

IVI: intravenous

Characteristics of excluded studies [ordered by study ID]

\begin{tabular}{ll}
\hline Study & Reason for exclusion \\
\hline Besio 1994 & $\begin{array}{l}\text { Controlled trial of ECV at term, not randomised. Cephalic presentation at term in } 32 / 45 \text { versus } 4 / 45 \\
\text { in the control group. Caesarean sections } 22 / 45 \text { versus } 39 / 45 \text { respectively. }\end{array}$ \\
\hline El-Muzaini 2008a & $\begin{array}{l}\text { This is an abstract from a conference presentation of intrapartum ECV (30 women) without tocol- } \\
\text { ysis compared to no ECV attempt (30 women). No mention of whether randomisation was used in } \\
\text { group allocation. Attempts to contact authors for clarification failed. }\end{array}$ \\
\hline El-Muzaini 2008b & $\begin{array}{l}\text { This is an abstract from a conference presentation of outpatient ECV without tocolysis (40 women) } \\
\text { compared to no ECV attempt (47 women) in women with a singleton breech and } 1 \text { previous lower } \\
\text { segment caesarean section. No mention of whether randomisation was used in group allocation. } \\
\text { Attempts to contact authors for clarification failed. }\end{array}$ \\
\hline Rust 2005 & $\begin{array}{l}\text { This randomised trial compares late ECV with early ECV. } \\
\text { Stine } 1985\end{array}$ \\
$\begin{array}{l}\text { Non-randomised follow-on study after completion of the Van Dorsten randomised trial. ECV was } \\
\text { successful in } 108 / 148 \text { women. } 6 \text { were lost to follow-up and } 7 \text { reverted to abnormal lies. Of the re- } \\
\text { maining 95, 23 underwent caesarean section. } 1 \text { unexplained intrauterine death occurred } 3 \text { weeks } \\
\text { after successful ECV. } 1 \text { maternal death occurred at caesarean section } 4 \text { days after successful ECV, } \\
\text { from amnionitis, septicaemia, intravascular coagulation and amniotic fluid embolus. }\end{array}$ \\
\hline Van Veelen 1989 \\
$\begin{array}{l}\text { Excluded because ECV attempts commenced at 33 weeks, and continued up to term. See review } \\
\text { 'External cephalic version for ECV before term' (Hutton 2006). }\end{array}$ \\
\hline
\end{tabular}

ECV: external cephalic version

DATA AND ANALYSES 
Comparison 1. External cephalic version at term versus no ECV attempt

\begin{tabular}{|c|c|c|c|c|}
\hline Outcome or subgroup title & No. of studies & $\begin{array}{l}\text { No. of partici- } \\
\text { pants }\end{array}$ & Statistical method & Effect size \\
\hline $\begin{array}{l}1 \text { Vaginal cephalic birth not } \\
\text { achieved (CS + breech vaginal birth) } \\
\text { (not prespecified) }\end{array}$ & 7 & 1253 & $\begin{array}{l}\text { Risk Ratio (M-H, Random, } \\
95 \% \mathrm{Cl})\end{array}$ & $0.46[0.33,0.62]$ \\
\hline 2 Caesarean section & 8 & 1305 & $\begin{array}{l}\text { Risk Ratio (M-H, Random, } \\
95 \% \mathrm{Cl})\end{array}$ & $0.57[0.40,0.82]$ \\
\hline 3 Non-cephalic presentation at birth & 8 & 1305 & $\begin{array}{l}\text { Risk Ratio (M-H, Random, } \\
95 \% \mathrm{Cl})\end{array}$ & $0.42[0.29,0.61]$ \\
\hline $\begin{array}{l}4 \text { Vaginal breech birth (not prespec- } \\
\text { ified) }\end{array}$ & 7 & 685 & $\begin{array}{l}\text { Risk Ratio (M-H, Random, } \\
95 \% \mathrm{CI})\end{array}$ & $0.35[0.24,0.50]$ \\
\hline $\begin{array}{l}5 \text { Apgar score }<7 \text { at } 1 \text { minute (not } \\
\text { prespecified) }\end{array}$ & 3 & 168 & $\begin{array}{l}\text { Risk Ratio (M-H, Random, } \\
95 \% \mathrm{Cl})\end{array}$ & $0.67[0.32,1.37]$ \\
\hline 6 Apgar score $<7$ at 5 minutes & 5 & 428 & $\begin{array}{l}\text { Risk Ratio (M-H, Fixed, 95\% } \\
\mathrm{Cl})\end{array}$ & $0.63[0.29,1.36]$ \\
\hline 7 Umbilical vein $\mathrm{pH}<7.20$ & 1 & 52 & $\begin{array}{l}\text { Risk Ratio (M-H, Fixed, 95\% } \\
\mathrm{Cl})\end{array}$ & $0.65[0.17,2.44]$ \\
\hline 8 Perinatal death & 8 & 1305 & $\begin{array}{l}\text { Risk Ratio (M-H, Fixed, 95\% } \\
\mathrm{Cl} \text { ) }\end{array}$ & $0.39[0.09,1.64]$ \\
\hline 9 Neonatal admission & 4 & 368 & $\begin{array}{l}\text { Risk Ratio (M-H, Fixed, 95\% } \\
\mathrm{Cl})\end{array}$ & $0.80[0.48,1.34]$ \\
\hline $\begin{array}{l}10 \text { Enrolment-delivery interval (not } \\
\text { prespecified) }\end{array}$ & 2 & 256 & $\begin{array}{l}\text { Mean Difference (IV, Fixed, } \\
95 \% \mathrm{CI})\end{array}$ & $-0.25[-2.81,2.31]$ \\
\hline
\end{tabular}

Analysis 1.1. Comparison 1 External cephalic version at term versus no ECV attempt, Outcome 1 Vaginal cephalic birth not achieved (CS + breech vaginal birth) (not prespecified).

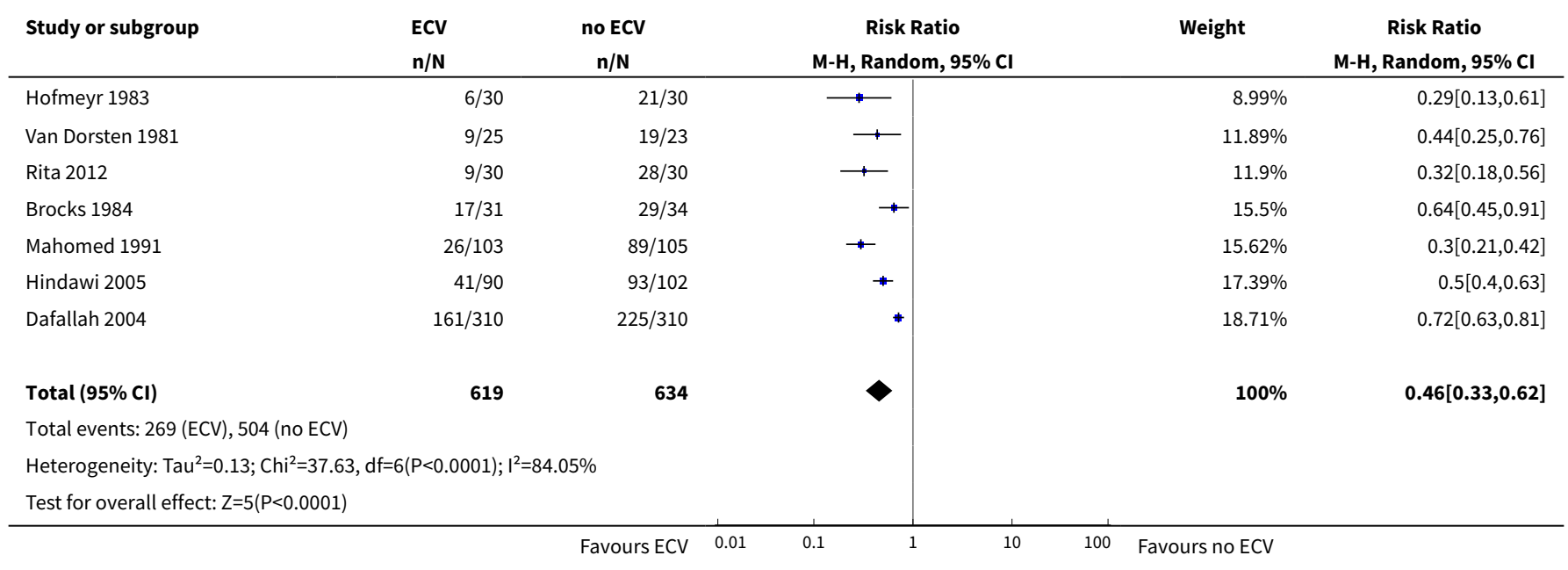


Analysis 1.2. Comparison 1 External cephalic version at term versus no ECV attempt, Outcome 2 Caesarean section.

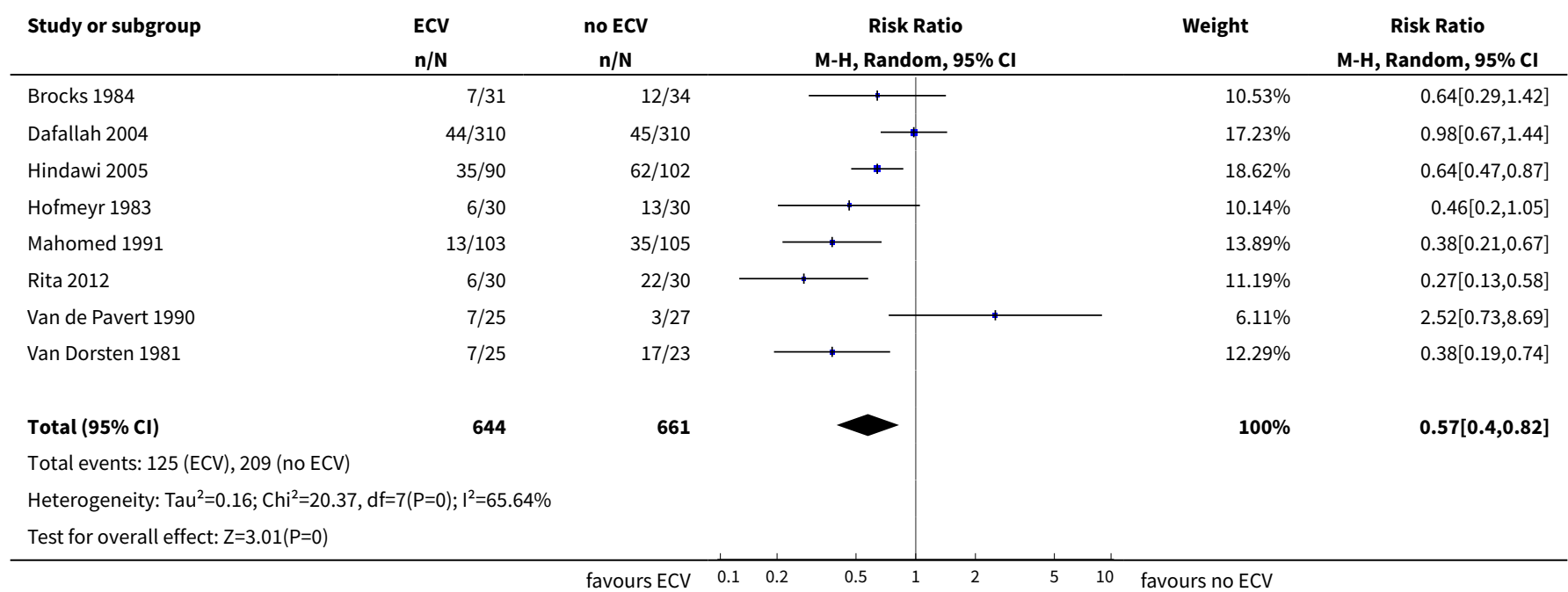

Analysis 1.3. Comparison 1 External cephalic version at term versus no ECV attempt, Outcome 3 Non-cephalic presentation at birth.

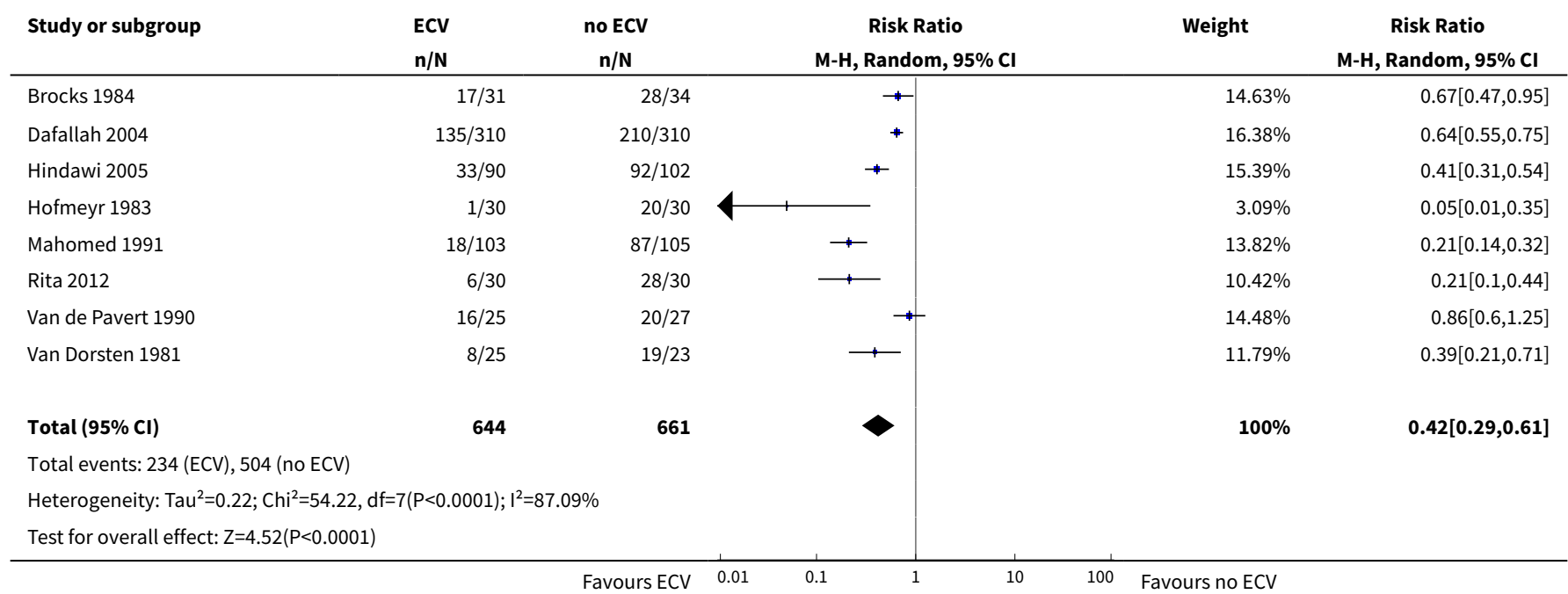

Analysis 1.4. Comparison 1 External cephalic version at term versus no ECV attempt, Outcome 4 Vaginal breech birth (not prespecified).

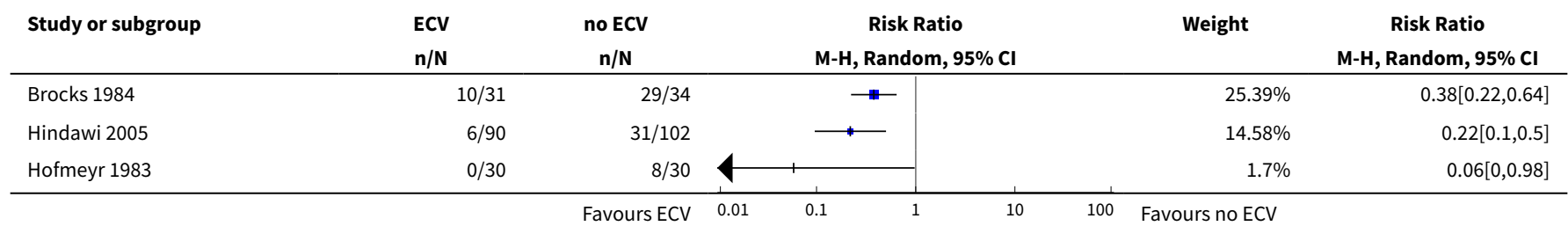




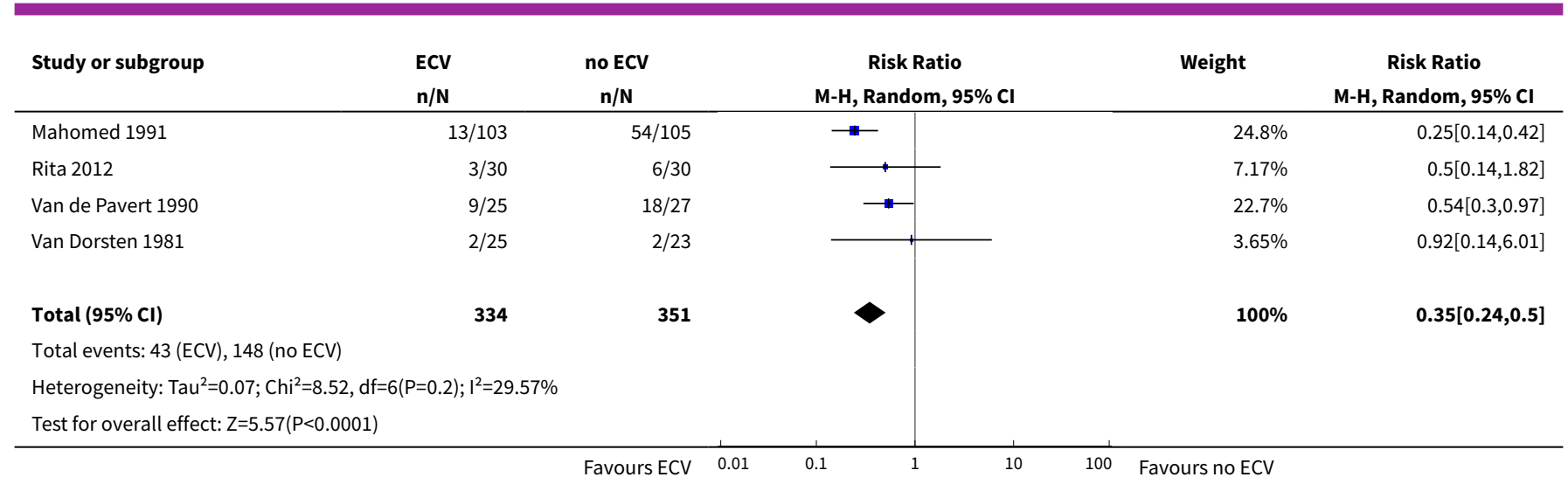

Analysis 1.5. Comparison 1 External cephalic version at term versus no ECV attempt, Outcome 5 Apgar score $<7$ at 1 minute (not prespecified).

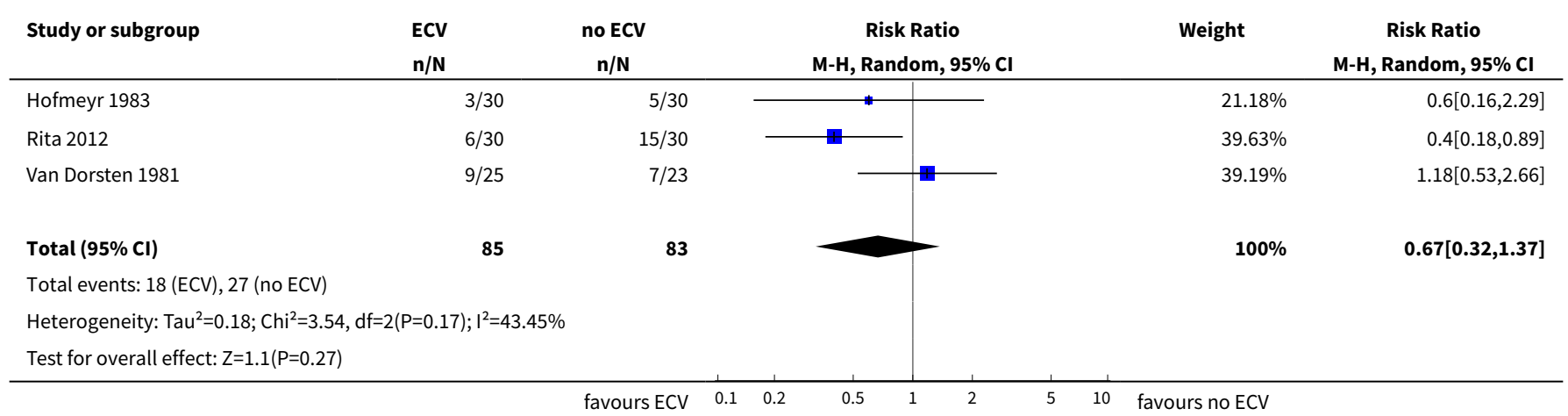

Analysis 1.6. Comparison 1 External cephalic version at term versus no ECV attempt, Outcome 6 Apgar score $<7$ at 5 minutes.

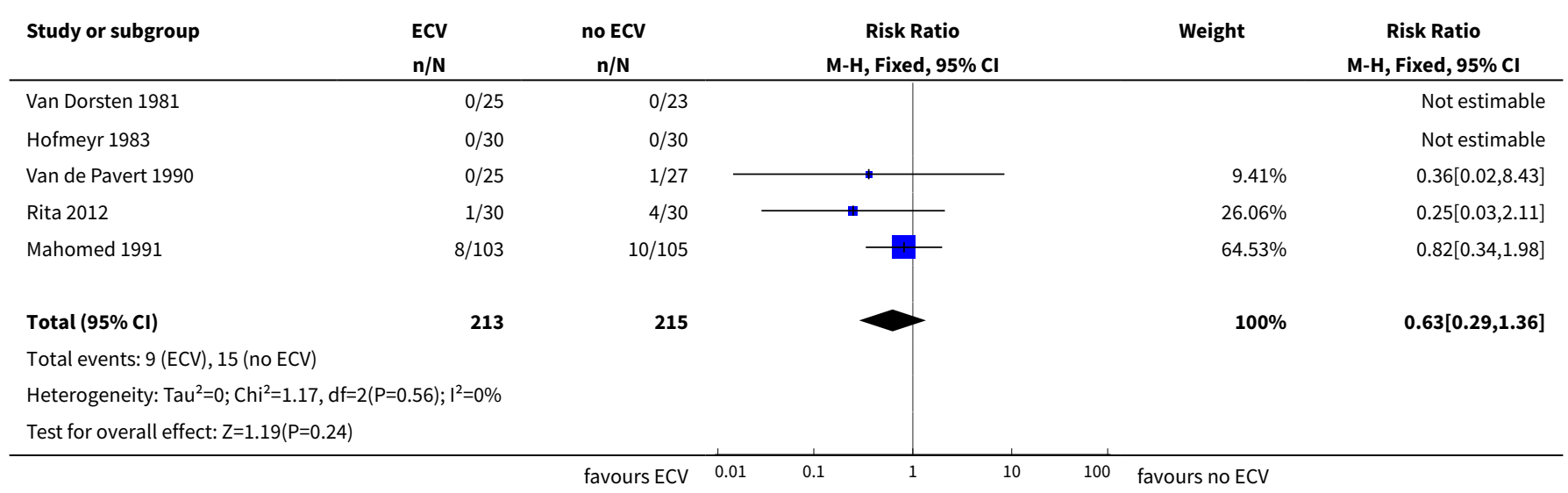


Analysis 1.7. Comparison 1 External cephalic version at term versus no ECV attempt, Outcome 7 Umbilical vein $\mathrm{pH}<7.20$.

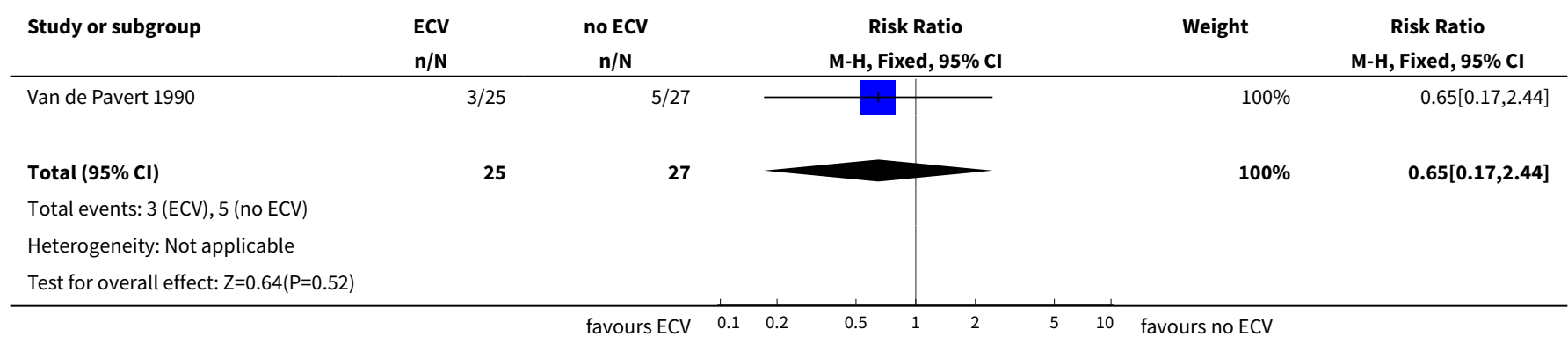

Analysis 1.8. Comparison 1 External cephalic version at term versus no ECV attempt, Outcome 8 Perinatal death.

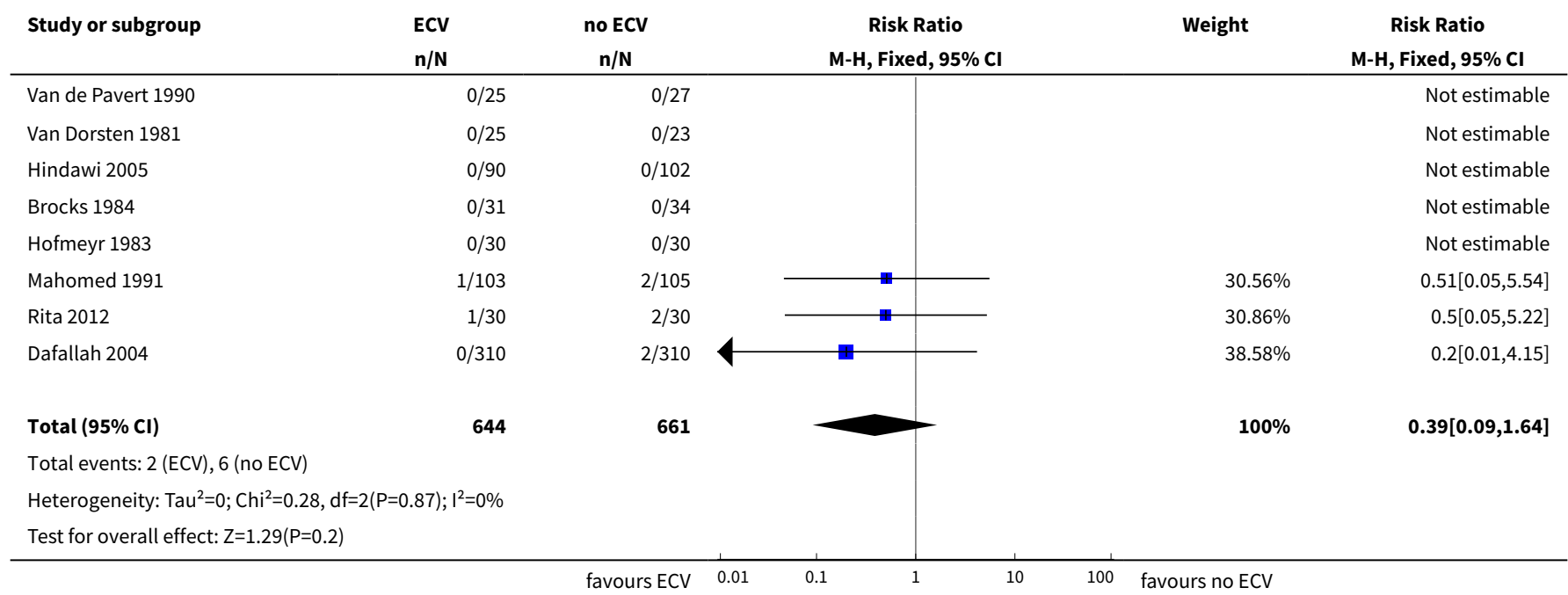

Analysis 1.9. Comparison 1 External cephalic version at term versus no ECV attempt, Outcome 9 Neonatal admission.

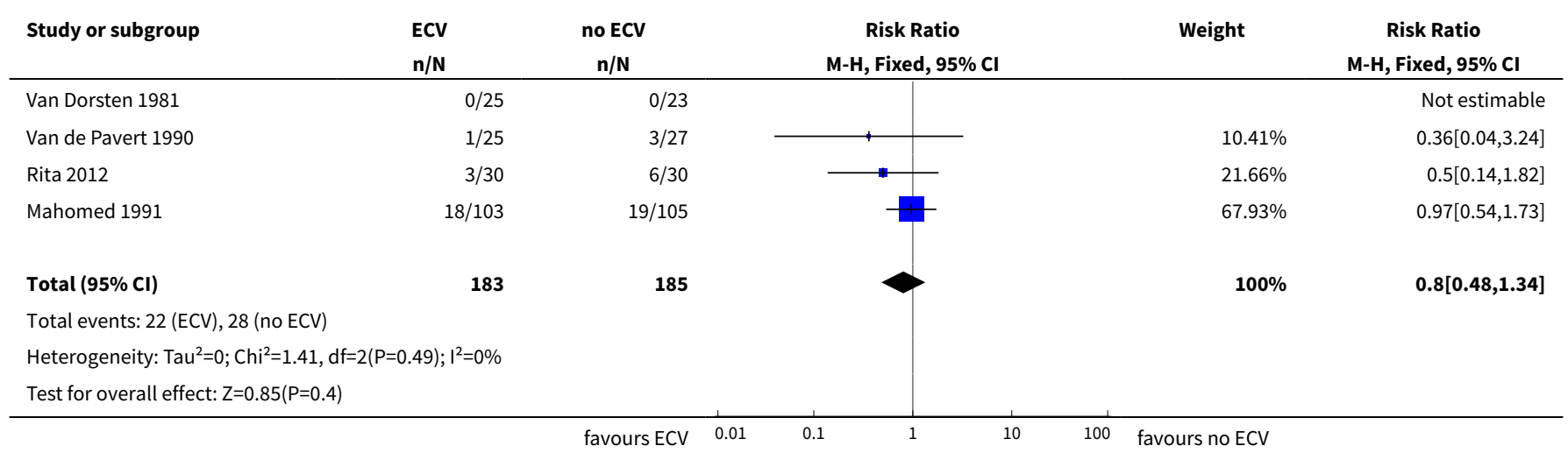


Analysis 1.10. Comparison 1 External cephalic version at term versus no ECV attempt, Outcome 10 Enrolment-delivery interval (not prespecified).

\begin{tabular}{|c|c|c|c|c|c|c|c|}
\hline \multirow[t]{2}{*}{ Study or subgroup } & \multicolumn{2}{|c|}{ ECV } & \multicolumn{2}{|c|}{ no ECV } & \multirow{2}{*}{$\begin{array}{c}\text { Mean Difference } \\
\text { Fixed, } 95 \% \mathrm{Cl}\end{array}$} & \multirow[t]{2}{*}{ Weight } & \multirow{2}{*}{$\begin{array}{c}\text { Mean Difference } \\
\text { Fixed, } 95 \% \mathrm{Cl}\end{array}$} \\
\hline & $\mathbf{N}$ & Mean(SD) & $\mathbf{N}$ & Mean(SD) & & & \\
\hline Mahomed 1991 & 103 & $14(11)$ & 105 & $14(9)$ & & $87.55 \%$ & $0[-2.73,2.73]$ \\
\hline Van Dorsten 1981 & 25 & $15.6(11.5)$ & 23 & $17.6(13.9)$ & & $12.45 \%$ & $-2[-9.25,5.25]$ \\
\hline 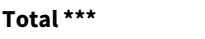 & 128 & & 128 & & & $100 \%$ & $-0.25[-2.81,2.31]$ \\
\hline \multicolumn{8}{|c|}{ Heterogeneity: $\operatorname{Tau}^{2}=0 ; \mathrm{Chi}^{2}=0.26, \mathrm{df}=1(\mathrm{P}=0.61) ; \mathrm{I}^{2}=0 \%$} \\
\hline \multicolumn{3}{|c|}{ Test for overall effect: $Z=0.19(P=0.85)$} & & & & & \\
\hline
\end{tabular}

\section{Comparison 2. Sensitivity analysis (excluding studies with high risk of bias)}

\begin{tabular}{lllll}
\hline Outcome or subgroup title & No. of studies & $\begin{array}{l}\text { No. of partici- } \\
\text { pants }\end{array}$ & Statistical method & Effect size \\
\hline $\begin{array}{l}1 \text { Vaginal cephalic birth not } \\
\text { achieved (CS + breech vaginal birth) }\end{array}$ & 4 & 376 & $\begin{array}{l}\text { Risk Ratio (M-H, Random, 95\% } \\
\text { Cl) }\end{array}$ & $0.32[0.25,0.41]$ \\
\hline 2 Caesarean section & 5 & 428 & $\begin{array}{l}\text { Risk Ratio (M-H, Random, 95\% } \\
\text { Cl) }\end{array}$ & $0.46[0.27,0.79]$ \\
\hline 3 Non cephalic presentation at birth & 5 & 428 & $\begin{array}{l}\text { Risk Ratio (M-H, Random, 95\% } \\
\text { Cl) }\end{array}$ & $0.29[0.12,0.68]$ \\
\hline 4 Vaginal breech birth & 5 & 428 & $\begin{array}{l}\text { Risk Ratio (M-H, Random, 95\% } \\
\text { Cl) }\end{array}$ & $0.38[0.21,0.69]$ \\
\hline
\end{tabular}

Analysis 2.1. Comparison 2 Sensitivity analysis (excluding studies with high risk of bias), Outcome 1 Vaginal cephalic birth not achieved (CS + breech vaginal birth).

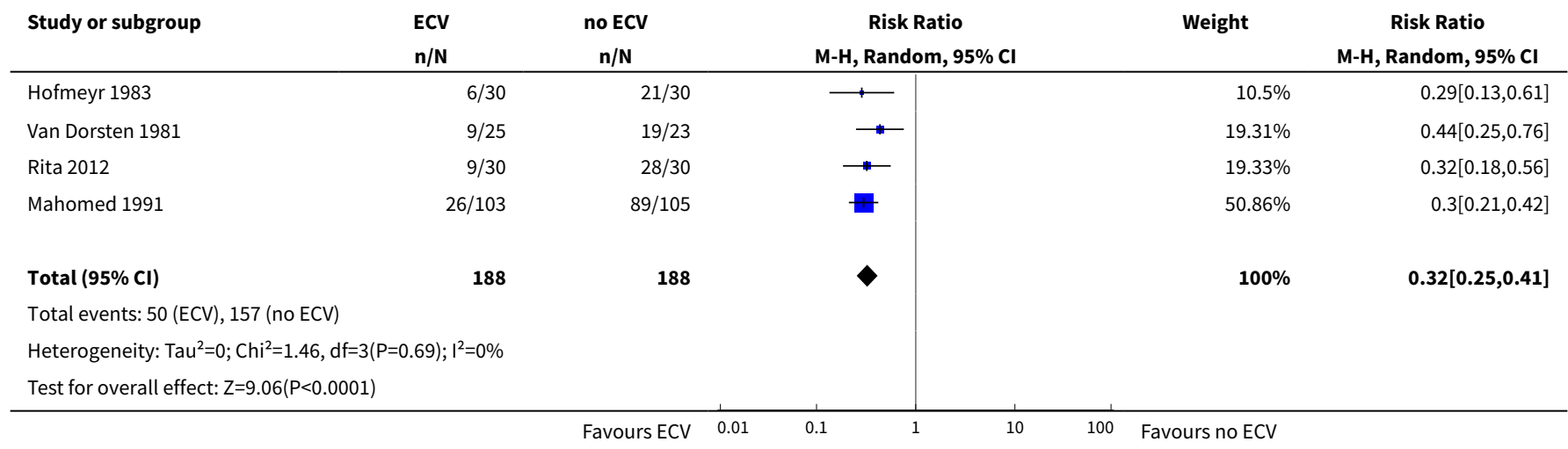


Analysis 2.2. Comparison 2 Sensitivity analysis (excluding studies with high risk of bias), Outcome 2 Caesarean section.

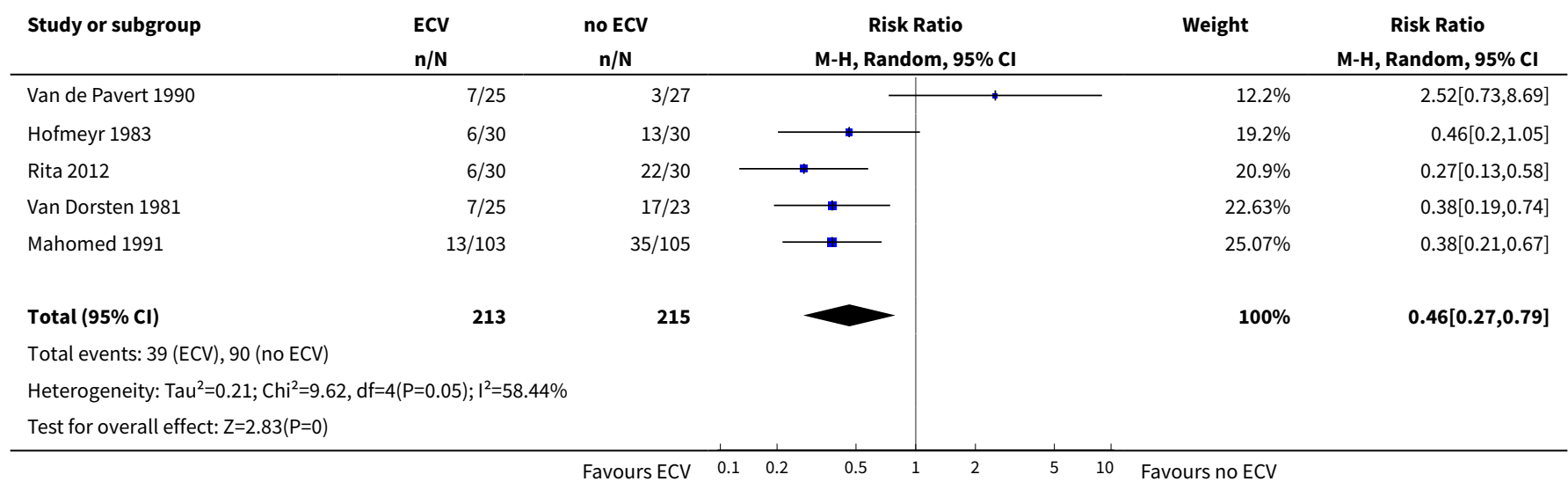

Analysis 2.3. Comparison 2 Sensitivity analysis (excluding studies with high risk of bias), Outcome 3 Non cephalic presentation at birth.

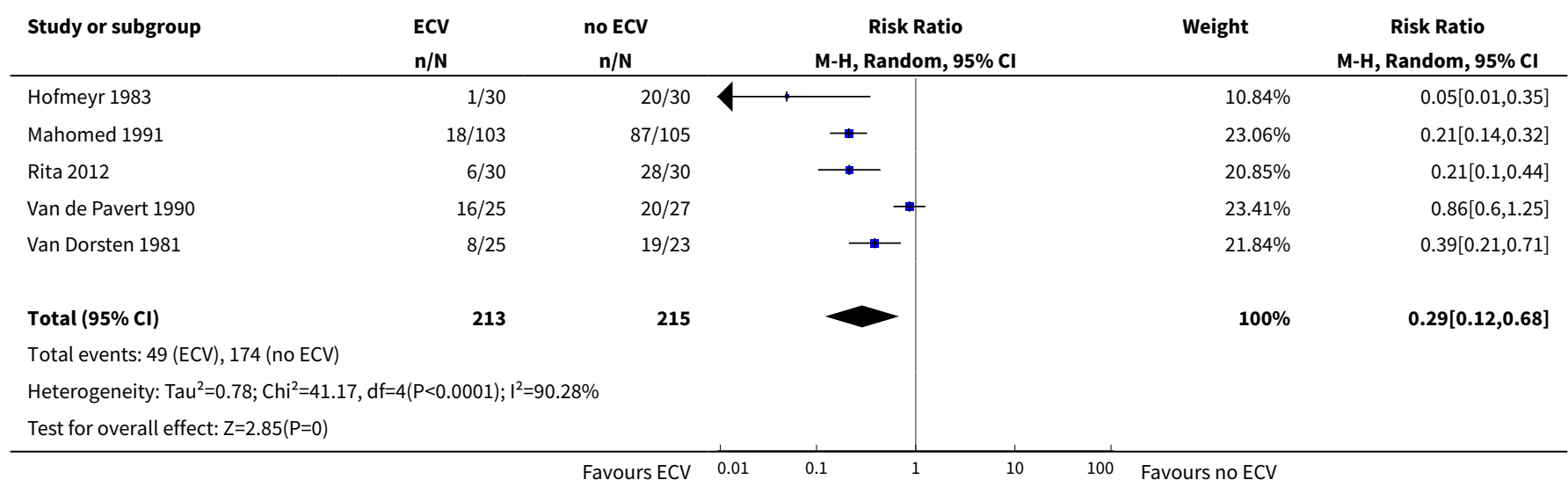

Analysis 2.4. Comparison 2 Sensitivity analysis (excluding

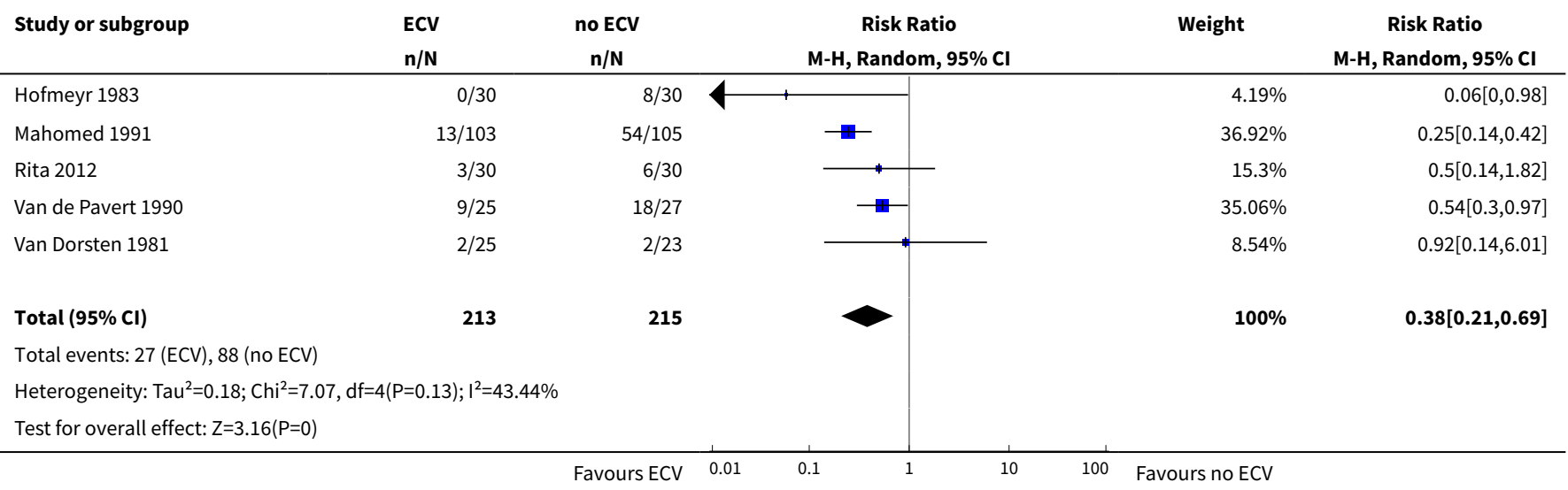


Comparison 3. Sensitivity analysis (excluding studies in Africa)

\begin{tabular}{llllll}
\hline Outcome or subgroup title & No. of studies & $\begin{array}{l}\text { No. of partici- } \\
\text { pants }\end{array}$ & Statistical method & Effect size \\
\hline $\begin{array}{l}1 \text { Vaginal cephalic birth not } \\
\text { achieved (CS + breech vaginal birth) }\end{array}$ & 4 & 365 & Risk Ratio (M-H, Fixed, 95\% Cl) & $0.49[0.41,0.58]$ \\
\hline 2 Caesarean section & 5 & 417 & Risk Ratio (M-H, Fixed, 95\% Cl) & $0.57[0.45,0.73]$ \\
\hline 3 Non cephalic presentation at birth & 5 & 417 & Risk Ratio (M-H, Fixed, 95\% Cl) & $0.46[0.39,0.55]$ \\
\hline 4 Vaginal breech birth & 5 & 417 & Risk Ratio (M-H, Fixed, 95\% Cl) & $0.38[0.27,0.54]$ \\
\hline
\end{tabular}

Analysis 3.1. Comparison 3 Sensitivity analysis (excluding studies in Africa), Outcome 1 Vaginal cephalic birth not achieved (CS + breech vaginal birth).

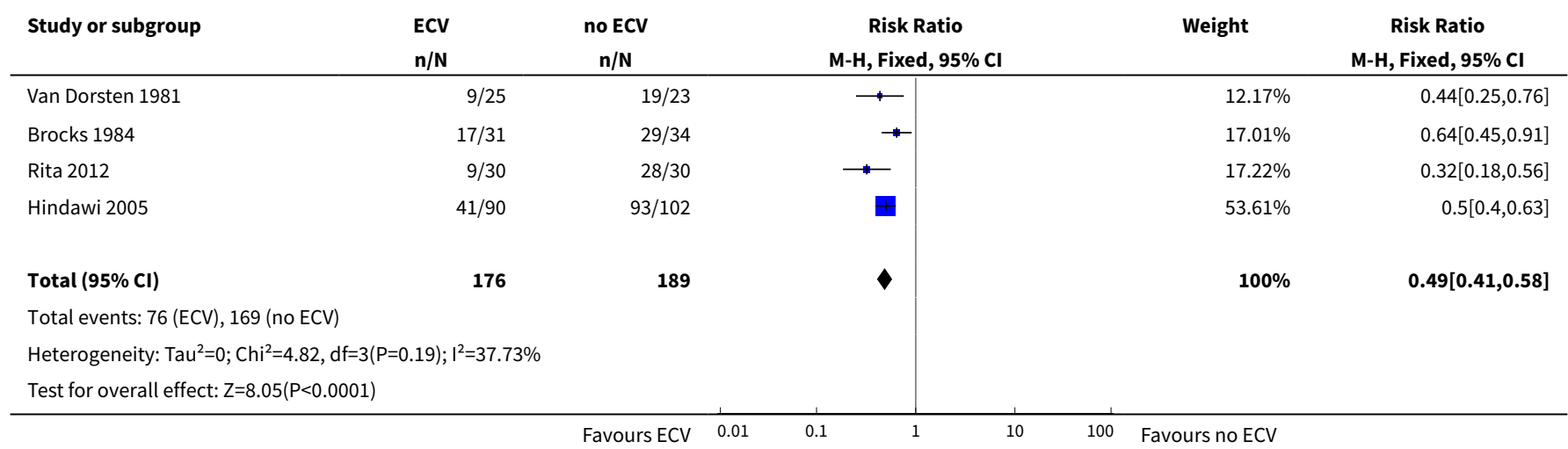

Analysis 3.2. Comparison 3 Sensitivity analysis (excluding studies in Africa), Outcome 2 Caesarean section.

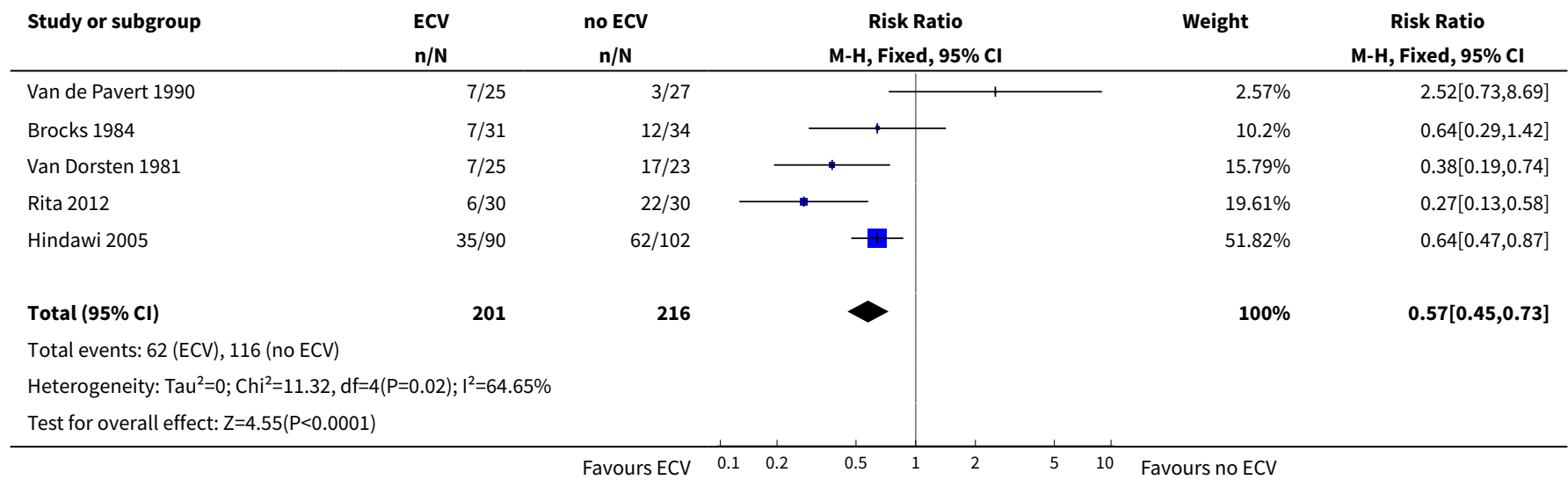


Analysis 3.3. Comparison 3 Sensitivity analysis (excluding studies in Africa), Outcome 3 Non cephalic presentation at birth.

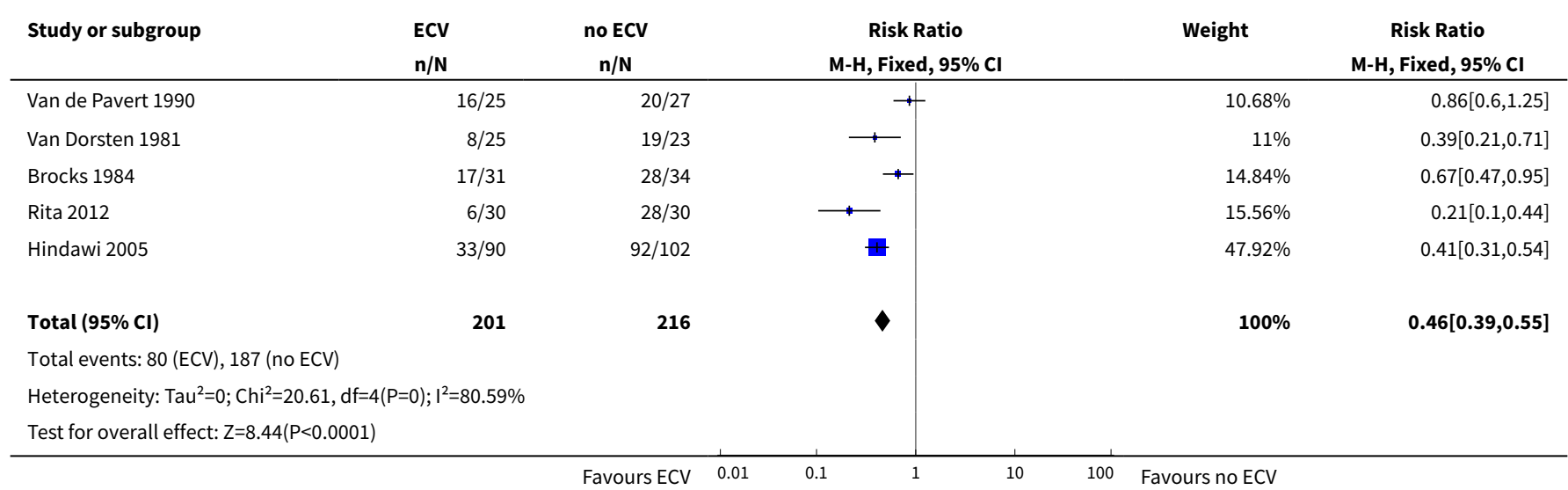

Analysis 3.4. Comparison 3 Sensitivity analysis (excluding studies in Africa), Outcome 4 Vaginal breech birth.

\begin{tabular}{|c|c|c|c|c|c|}
\hline Study or subgroup & $\begin{array}{l}\mathrm{ECV} \\
\mathrm{n} / \mathrm{N}\end{array}$ & $\begin{array}{c}\text { no ECV } \\
n / N\end{array}$ & $\begin{array}{c}\text { Risk Ratio } \\
\text { M-H, Fixed, } 95 \% \mathrm{CI}\end{array}$ & Weight & $\begin{array}{c}\text { Risk Ratio } \\
\text { M-H, Fixed, } 95 \% \mathrm{Cl}\end{array}$ \\
\hline Van Dorsten 1981 & $2 / 25$ & $2 / 23$ & - & $2.54 \%$ & $0.92[0.14,6.01]$ \\
\hline Rita 2012 & $3 / 30$ & $6 / 30$ & $\longrightarrow$ & $7.31 \%$ & $0.5[0.14,1.82]$ \\
\hline Van de Pavert 1990 & $9 / 25$ & $18 / 27$ & $\longrightarrow$ & $21.08 \%$ & $0.54[0.3,0.97]$ \\
\hline Brocks 1984 & $10 / 31$ & $29 / 34$ & $\rightarrow$ & $33.69 \%$ & $0.38[0.22,0.64]$ \\
\hline Hindawi 2005 & $6 / 90$ & $31 / 102$ & 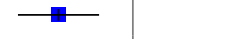 & $35.39 \%$ & $0.22[0.1,0.5]$ \\
\hline Total $(95 \% \mathrm{Cl})$ & 201 & 216 & & $100 \%$ & $0.38[0.27,0.54]$ \\
\hline \multicolumn{6}{|c|}{ Total events: 30 (ECV), 86 (no ECV) } \\
\hline \multicolumn{6}{|c|}{ Heterogeneity: $\mathrm{Tau}^{2}=0 ; \mathrm{Chi}^{2}=4.12, \mathrm{df}=4(\mathrm{P}=0.39) ; \mathrm{I}^{2}=2.85 \%$} \\
\hline \multicolumn{6}{|c|}{ Test for overall effect: $Z=5.49(P<0.0001)$} \\
\hline
\end{tabular}

\section{APPENDICES}

\section{Appendix 1. Previous searches conducted by authors}

CENTRAL (The Cochrane Library, 2010, Issue 3) and PubMed (1966 to September 2010) using the terms external cephalic version OR ECV.

\section{WHAT'S NEW}

\begin{tabular}{lll}
\hline Date & Event & Description \\
\hline 8 May 2019 & Amended & $\begin{array}{l}\text { Edited Justus Hofmeyr's Declarations of interest statement to in- } \\
\text { clude more information. }\end{array}$ \\
\hline
\end{tabular}

\section{HISTORY}

Protocol first published: Issue 2, 1996 
Review first published: Issue 2, 1996

\begin{tabular}{|c|c|c|}
\hline Date & Event & Description \\
\hline 21 March 2016 & Amended & Added a link (in abstract and PLS) to related infographic. \\
\hline 13 October 2015 & Amended & We have added a revised plain language summary. \\
\hline 11 June 2015 & Amended & Added Acknowledgements statement. \\
\hline 9 March 2015 & $\begin{array}{l}\text { New citation required but conclusions } \\
\text { have not changed }\end{array}$ & Review updated. The review now includes eight trials. \\
\hline 28 February 2015 & New search has been performed & $\begin{array}{l}\text { Search updated, one new trial identified and included (Rita } \\
\text { 2012), methods updated. A 'Summary of findings' table has been } \\
\text { added. }\end{array}$ \\
\hline 7 August 2012 & New search has been performed & Search updated. No new trial reports identified. \\
\hline 31 July 2012 & $\begin{array}{l}\text { New citation required but conclusions } \\
\text { have not changed }\end{array}$ & Review updated with new search date. \\
\hline 10 September 2010 & New search has been performed & $\begin{array}{l}\text { Search updated. Two new studies included (Dafallah 2004; Hin- } \\
\text { dawi 2005) and three studies excluded (Rust 2005; El-Muzaini } \\
\text { 2008a; El-Muzaini 2008b). Conclusions not changed. }\end{array}$ \\
\hline 2 July 2010 & Amended & Contact details edited. \\
\hline 2 September 2008 & Amended & Converted to new review format. \\
\hline 1 April 2005 & Amended & $\begin{array}{l}\text { Revised to be consistent with revision of review 'External cephal- } \\
\text { ic version for breech presentation before term' (Hutton 2006). } \\
\text { Van Veelen } 1989 \text { trial reassigned to the latter review. }\end{array}$ \\
\hline & & Search updated. No new trials identified. \\
\hline 31 December 2004 & New search has been performed & Literature search revised. No new data identified. \\
\hline
\end{tabular}

\section{CONTRIBUTIONSOF AUTHORS}

GJ Hofmeyr prepared the original version, maintains the review and reviewed the updated version. $\mathrm{H}$ West revised the text, assessed studies, extracted and analysed data for the updated version of the review. R Kulier assessed studies and extracted data for the updated version of the review, and revised and quality-checked the previous version of the review.

\section{DECLARATIONSOF INTEREST}

GJ Hofmeyr (GJH) is an author of one of the papers included in this review (Hofmeyr 1983) but he was not involved in assessing this study for inclusion, assessing trial quality, or data extraction. GJH receives royalties from UpToDate for chapters related to breech pregnancy, delivery of a baby in breech presentation and external cephalic version. UpToDate is an electronic publication by Wolters Kluwer to disseminate evidence-based medicine (such as Cochrane reviews).

\section{SOURCES OF SUPPORT}

\section{Internal sources}

- (GJH) Effective Care Research Unit, University of the Witwatersrand/Fort Hare, Eastern Cape Department of Health, South Africa.

- Department of Obstetrics and Gynaecology, Geneva University Hospital, Switzerland. 
- (HW) Cochrane Pregnancy and Childbirth Group, Department of Women's and Children's Health, The University of Liverpool, Liverpool, UK.

\section{External sources}

- (GJH) South African Medical Research Council, South Africa.

- (GJH) HRP-UNDP/UNFPA/WHO/World Bank Special Programme in Human Reproduction, Geneva, Switzerland.

- Rockefeller Foundation, USA.

- (HW) National Institute for Health Research (NIHR), UKNIHR Cochrane Programme Grant Project: 13/89/05 - Pregnancy and childbirth systematic reviews to support clinical guidelines, UK.

\section{DIFFERENCES BETWEEN PROTOCOLAND REVIEW}

The outcomes vaginal cephalic delivery not achieved and vaginal breech delivery were added for this 2015 update. Outcomes that were not prespecified in the original protocol include: vaginal cephalic delivery not achieved, vaginal breech delivery, Apgar score less than seven at one minute, and enrolment-delivery interval.

Methods for subgroup analysis for future updates were added. It has been suggested that ECV may be more successful (and spontaneous version more common) in black African than Caucasian women, possibly because of the tendency for the presenting part to remain high until the onset of labour (Hofmeyr 1986). Post-hoc sensitivity analysis excluding the three studies in black African women (Dafallah 2004; Hofmeyr 1983; Mahomed 1991) was conducted.

\section{INDEX TERMS}

\section{Medical Subject Headings (MeSH)}

*Breech Presentation; *Term Birth; Cesarean Section; Pregnancy Outcome; Randomized Controlled Trials as Topic; Version, Fetal $\left[{ }^{*}\right.$ methods $]$

\section{MeSH check words}

Female; Humans; Pregnancy 